\title{
Variations of the Atlantic meridional overturning circulation in control and transient simulations of the last millennium
}

\author{
D. Hofer ${ }^{1,2}$, C. C. Raible ${ }^{1,2}$, and T. F. Stocker ${ }^{1,2}$ \\ ${ }^{1}$ Climate and Environmental Physics, Physics Institute, University of Bern, Bern, Switzerland \\ ${ }^{2}$ Oeschger Centre for Climate Change Research, University of Bern, Bern, Switzerland \\ Received: 22 June 2010 - Published in Clim. Past Discuss.: 7 July 2010 \\ Revised: 17 January 2011 - Accepted: 21 January 2011 - Published: 28 February 2011
}

\begin{abstract}
The variability of the Atlantic meridional overturing circulation (AMOC) strength is investigated in control experiments and in transient simulations of up to the last millennium using the low-resolution Community Climate System Model version 3. In the transient simulations the AMOC exhibits enhanced low-frequency variability that is mainly caused by infrequent transitions between two semistable circulation states which amount to a 10 percent change of the maximum overturning. One transition is also found in a control experiment, but the time-varying external forcing significantly increases the probability of the occurrence of such events though not having a direct, linear impact on the AMOC. The transition from a high to a low AMOC state starts with a reduction of the convection in the Labrador and Irminger Seas and goes along with a changed barotropic circulation of both gyres in the North Atlantic and a gradual strengthening of the convection in the Greenland-IcelandNorwegian (GIN) Seas. In contrast, the transition from a weak to a strong overturning is induced by decreased mixing in the GIN Seas. As a consequence of the transition, regional sea surface temperature (SST) anomalies are found in the midlatitude North Atlantic and in the convection regions with an amplitude of up to $3 \mathrm{~K}$. The atmospheric response to the SST forcing associated with the transition indicates a significant impact on the Scandinavian surface air temperature (SAT) in the order of $1 \mathrm{~K}$. Thus, the changes of the ocean circulation make a major contribution to the Scandinavian SAT variability in the last millennium.
\end{abstract}

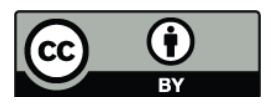

Correspondence to: D. Hofer (dhofer@climate.unibe.ch)

\section{Introduction}

The Atlantic meridional overturning circulation (AMOC) is an important pacemaker for the climate in the North Atlantic region. Paleo-proxy records and model results suggest that abrupt climate changes during the last glaciation are linked to changes in the AMOC strength (Stocker, 2000; Clark et al., 2002; Schmittner et al., 2003). For more recent times, observational studies indicate basin-wide sea surface temperature (SST) variations in the North Atlantic, known as the Atlantic multidecadal oscillation (AMO), which are likely related to the AMOC strength (Hurrell et al., 2006, and references therein). Moreover, it was shown that the AMO is linked to changes of the European and North American climate (Enfield et al., 2001; Sutton and Hodson, 2005).

A good understanding of AMOC variations and their climatic impact also in the model world is essential. In this study, we investigate and characterize the differences in the AMOC between several control simulations and an ensemble of transient simulations with time-varying forcing in a comprehensive atmosphere-ocean general circulation model (AOGCM). In addition, the atmospheric response to the lowfrequency variations of the AMOC is investigated. The transient simulations cover up to the last millennium, so that the focus is set more on natural variations of the external forcing than on the anthropogenic impact.

In control simulations of many AOGCMs multidecadal oscillations of the AMOC are found (e.g., Delworth et al., 1993; Timmermann et al., 1998; Dong and Sutton, 2005; Jungclaus et al., 2005; Danabasoglu, 2008). However, the length of the periods and the derived mechanisms considerably diverge between the models. For example, Danabasoglu (2008) presents an AMOC oscillation with a 21-yr period for the high-resolution Community Climate System Model version 3 (CCSM3), whereas for the ECHAM5/MPI-OM the dominant

Published by Copernicus Publications on behalf of the European Geosciences Union. 
period of the oscillation is about 70-80 years (Jungclaus et al., 2005) similar to earlier model studies (Delworth et al., 1993). Some studies argue that the oscillation is an oceanonly mode which is driven by density anomalies in the deep water formation (DWF) regions (e.g., Delworth et al., 1993; Jungclaus et al., 2005). Others suggest an internal ocean mode that is excited by atmospheric noise (e.g., Frankcombe et al., 2010) or a coupled ocean-atmosphere mode involving the North Atlantic Oscillation (e.g., Timmermann et al., 1998; Danabasoglu, 2008).

In simulations with an increasing level of greenhouse gases (GHGs), most AOGCMs show a gradual weakening of the AMOC (IPCC, 2007). A model intercomparison study indicates that the weakening is mainly caused by changes in the surface heat flux (Gregory et al., 2005). Also for the CCSM3, which is used in this study, simulations with an idealized $\mathrm{CO}_{2}$ increase of $1 \%$ per year (Bryan et al., 2006) and scenario based projections of the 21st century (Meehl et al., 2006) show a weakening of the AMOC. However, the less pronounced GHGs increases in the 20th century do not result in a significant change of the AMOC (Meehl et al., 2006).

The impact of total solar irradiance (TSI) changes on the AMOC has attracted less attention. Generally, an increase in TSI is proposed to weaken the AMOC similarly to the response to an increase in the atmospheric $\mathrm{CO}_{2}$ content (Goosse and Renssen, 2006). For the TSI variations in the last millennium, however, this relationship is less clear. In some simulations a strong negative correlation is found when the AMOC lags the TSI by a few decades (Cubasch et al., 1997; van der Schrier et al., 2002), while in another simulation the TSI does not have a significant impact on the AMOC (Zorita et al., 2004). A possible explanation for the divergence could be a masking of the solar forcing signal by internal variability, as suggested by the results of van der Schrier et al. (2002), who find a much lower correlation of AMOC with weak TSI changes compared to strong TSI changes. The AMOC response to volcanic forcing has been even less investigated. The available AOGCM studies indicate a strengthening of the AMOC after strong volcanic eruptions (equivalent to the Tambora and Pinatubo eruptions) in the order of 10\% (Stenchikov et al., 2009; Ottera et al., 2010).

A direct comparison of the AMOC in unforced control simulations and in transient simulations has already been made in other studies (Dai et al., 2005; D'Orgeville and Peltier, 2009). For the Parallel Climate Model, Dai et al. (2005) highlight the similarities of the process that lead to AMOC variations in a control simulation and to a decrease of the AMOC in several global warming simulations. In both cases the AMOC changes are induced by upper-ocean density anomalies and accompanied by a shift of the Gulf Stream and the North Atlantic Current (NAC). In D'Orgeville and Peltier (2009) the focus is set on the impact of different external forcing levels and different warming scenarios on the AMOC variability in the CCSM3. They show that the mechanism for AMOC variations is similar in the control simulations and in a moderate warming scenario (historical 1870-2000 simulation), namely a delayed response to salinity anomalies at the DWF sites of the subpolar gyre. For strong warming simulations, however, such a relationship is no longer found.

So far, the model results suggest a significant response of the AMOC to strong forcing changes (e.g., IPCC, 2007; Goosse and Renssen, 2006; Stenchikov et al., 2009), whereas the impact of moderate forcing variations is less clear (e.g., Zorita et al., 2004; Meehl et al., 2006). The results of D'Orgeville and Peltier (2009) indicate that the mechanism that drives the AMOC variations may change depending on the amplitude of the forcing. Therefore, it is useful to investigate the effect of small variations in the external forcing level (as found in the last millennium) on the AMOC.

The paper is organized as follows: in Sect. 2, the model and the experiments are briefly described. The results are presented in Sect. 3. A summary and the discussion are given in Sect. 4.

\section{Model description and experiments}

The CCSM3 was developed by the National Center for Atmospheric Research (NCAR). It is a coupled model with no flux corrections and consists of four components: atmosphere, ocean, sea ice, and land surface (Collins et al., 2006a). To perform centennial timescale simulations the lowest resolution configuration (Yeager et al., 2006) for the model components is chosen: the atmospheric component uses a T31 spectral truncation, corresponding to a horizontal grid of approximately $3.75^{\circ}$ by $3.75^{\circ}$ and 26 hybrid sigmapressure levels (Collins et al., 2006b). The land surface component has the same horizontal resolution as the atmosphere (Oleson et al., 2004). The grid for the ocean component has a nominal resolution of $3^{\circ}\left(3.6^{\circ}\right.$ in longitude and $0.6^{\circ}$ to $2.8^{\circ}$ in latitude with better refinement in the Tropics and near Greenland) with 25 vertical levels, whose thickness increases from $8 \mathrm{~m}$ at the top to $500 \mathrm{~m}$ in the deep ocean (Smith and Gent, 2004). It is a dipole grid where one pole is located at the South Pole and the other pole is located over Greenland. Ocean dynamics are based on the primitive equations using the hydrostatic and the Bousinesq approximations. The sea ice component uses the same horizontal grid of the ocean component and a sub-grid scale ice thickness distribution which is parametrized using five thickness categories (Briegleb et al., 2004). Further information about the model and its components are provided at the CCSM web page (www.ccsm.ucar.edu).

An overview of the CCSM3 experiments is given in Table 1. In principle, two setups are chosen: (i) control simulations (CTRL) where the external forcing is kept constant, and (ii) transient simulations (TR) with timevarying forcing. 
Table 1. List of all experiments. Note that the length for the CTRL1500 and the CTRL1000 simulation also includes the 50 yrs that were not used in the analysis.

\begin{tabular}{llrl}
\hline Label & Description & Length (yrs) & Branched from (yr) \\
\hline CTRL1990 & 1990 A.D. equilibrium simulation (NCAR) & 480 & - \\
CTRL1500 & 1500 A.D. equilibrium simulation & 692 & CTRL1990 (100) \\
CTRL1000 & 1000 A.D. equilibrium simulation & 1318 & TRa4 (1617 A.D.) \\
TRa1 & Transient experiment (1500 to 2000 A.D.) & 500 & CTRL1500 (62) \\
TRa2 & Transient experiment (1500 to 2000 A.D.) & 500 & CTRL1500 (82) \\
TRa3 & Transient experiment (1500 to 2000 A.D.) & 500 & CTRL1500 (73) \\
TRa4 & Transient experiment (1500 to 2000 A.D.) & 500 & CTRL1500 (84) \\
TRb1 & Transient experiment (1000 to 2000 A.D.) & 1000 & CTRL1000 (200) \\
TRsulfate & Transient experiment including sulfate & 130 & TRb1 (1870 A.D.) \\
& aerosols (1870 to 2000 A.D.) & & \\
\hline
\end{tabular}

As control simulations, we conducted two experiments with the external forcing level appropriate for 1500 A.D. (CTRL1500) and 1000 A.D. (CTRL1000). Additionally, we consider parts of a 880 -yr present-day integration, that was conducted by the NCAR and is extended here by a few decades to check consistency. The last 480 years of the NCAR integration are used as a perpetual 1990 A.D. experiment (CTRL1990). An evaluation of the climate in the NCAR simulation can be found in Yeager et al. (2006). Compared to observations the simulated climate exhibits some major biases in the North Atlantic basin which will likely have an impact on the AMOC: the path of the NAC is too zonal, the northward heat transport is reduced, and the sea ice coverage is overestimated (Yeager et al., 2006). In addition, some deep water formation regions are not correctly represented, i.e., the convection region in the Labrador Sea is displaced to the southeast and the mixing in the GreenlandIceland-Norwegian (GIN) Seas is unrealistically low (Bryan et al., 2006). Nevertheless, the low-resolution CCSM3 has proven to provide useful information about the mechanisms of AMOC variations (D'Orgeville and Peltier, 2009; Renold et al., 2010; Yoshimori et al., 2010). The CTRL1500 simulation was initialized from the extended CTRL1990, whereas CTRL1000 was branched from one of the transient simulations. The first 50 years of these two control integrations were not used for the analysis to reduce the impact of adjustments to the change in forcing conditions. Nevertheless, the control simulations have a trend that is roughly linear for the atmosphere and for the sea surface and exhibits a converging structure in the deep ocean. To minimize the effect of the drift all variables from control simulations are detrended by removing a quadratic least-squares fit, which produces good results for all depth levels. Generally, the correction is the largest in the CTRL1500 simulation. There, the mean correction accounts for a $0.3 \mathrm{~Sv}\left(1 \mathrm{~Sv} \equiv 10^{6} \mathrm{~m}^{3} \mathrm{~s}^{-1}\right)$ decrease per century regarding the maximum AMOC compared to a decrease of $0.1 \mathrm{~Sv}$ per century in CTRL1000 and less than 0.1 Sv per century in CTRL1990.
Besides the control integrations, five transient simulations were conducted covering the last five centuries up to the last millennium. An ensemble of four simulations (TRa1 to TRa4) was integrated from 1500 to 2000 A.D. and one simulation (TRb1) was performed over the entire millennium. The initial states for the ensemble simulations were taken from different years of the CTRL1500 experiment and the millennial simulation was initialized from the CTRL1000 integration. The transient experiments are detrended using the correction of the initializing control simulation.

The time-varying external forcing in the transient simulations is composed of the solar forcing, GHGs concentrations $\left(\mathrm{CO}_{2}, \mathrm{~N}_{2} \mathrm{O}, \mathrm{CH}_{4}\right.$, and halocarbons) and volcanic aerosols. The solar forcing is implemented in the model as variations of the TSI. For 1000 to 1998 A.D., the amplitude of the TSI corresponds to the net radiative forcing $L_{\text {net }}$ of Crowley (2000), scaled to data of Lean et al. (1995), according to the relation TSI $=1365.0635 \mathrm{~W} \mathrm{~m}^{-2}+5.399 \times L_{\text {net }}$ (Yoshimori et al., 2010). For the last two years of the simulations, Active Cavity Radiometer Irradiance Monitor composite data (Fröhlich and Lean, 2004) are used, which have been adjusted to the pre 1998 A.D. forcing strength for a smooth transition. Note that the amplitude of the solar forcing variations used in the transient simulations is a factor 2 to 4 higher than reported in most recent reconstructions (e.g., Steinhilber et al., 2009). However, newest reconstructions show again a higher amplitude similar to the one used (Schmutz, pers. comm.). The GHGs concentrations are based on ice core reconstructions by Etheridge et al. (1996), Blunier et al. (1995), Flückiger et al. (1999), Flückiger et al. (2002), and - from 1970 onwards - on direct atmospheric measurements (Dlugokencky et al., 2003; Keeling and Whorf, 2005; Thompson et al., 2004). The combined radiative forcing (RF) of the TSI and the GHGs is shown in Fig. 1a, assuming a planetary albedo of 0.31 and using the conversion for GHGs given in IPCC (2001) Table 6.2.

For the volcanic forcing we converted the total solar irradiance changes due to volcanoes of Crowley (2000) to 
total aerosol masses, using linear regression coefficients obtained from the 6 strongest volcanic eruptions in the last 130 years (Ammann et al., 2003). The aerosols were latitudinally distributed in the lower stratosphere conserving the total amount. Two different types of distributions were considered for the transient simulations. In the TRa simulations, the volcanic aerosols were added in one layer between 100 to $140 \mathrm{hPa}$ (140 to $190 \mathrm{hPa}$ at higher latitudes) and the aerosol concentration was weighted by a latitudinal cosine function to account for the higher concentrations at low latitudes. In the TRb1 integration, a horizontally more complex distribution was used, similar to the mean distribution in Ammann et al. (2003). The aerosols were added over several layers and the maximum concentrations were located at 30 to $60 \mathrm{hPa}(60$ to $100 \mathrm{hPa}$ at higher latitudes). In both cases, the concentration of volcanic aerosols is set constant over the year, so all eruptions start at the beginning of the year, and the distribution pattern in one simulation does not differ from one eruption to the other. This rather rough implementation reflects the missing knowledge about the exact starting date and the aerosol distribution in the atmosphere for most of the eruptions. In Fig. $1 \mathrm{~b}$ the volcanic forcing time series is presented by changes of the optical depth in the visible band.

Note that we did not include anthropogenic sulfate emissions in the transient simulations. However, an additional experiment (TRsulfate) is performed to estimate the impact of these aerosols. The simulation covers the period 1870 to 2000 A.D. and includes anthropogenic sulfate emissions as in Meehl et al. (2006). The TRsulfate experiment is discussed only for the surface air temperature (SAT) of the Northern Hemisphere (NH), where it shows large differences compared to the other transient simulations.

Unless otherwise noted, we use annual mean values in the analysis. For the low-pass filtered time series, the annual values are smoothed with a Gaussian-weighted filter to remove fluctuations on time scales of less than 30 years. Due to the filtering procedure, the time series omit 15 years at both ends of the records.

\section{Results}

\subsection{Surface temperature}

The annual mean SAT of the NH in the simulations is in good qualitative agreement with the reconstructions (Fig. 2). The reconstructions and simulations show a generally warm first half of the millennium (TRb1 only), several distinct periods with lower temperatures in the mid 15th, in the 17th and in the early 19th century and a strong warming in the 20th century. The amplitude of the simulated pre-industrial SAT variability is in the reconstructed range. In the TRb1 simulations the warmest and coldest 30 years period prior to 1850 A.D. differ by $0.46 \mathrm{~K}$, which is only slightly more than the $0.38 \mathrm{~K}$ found in Frank et al. (2010).
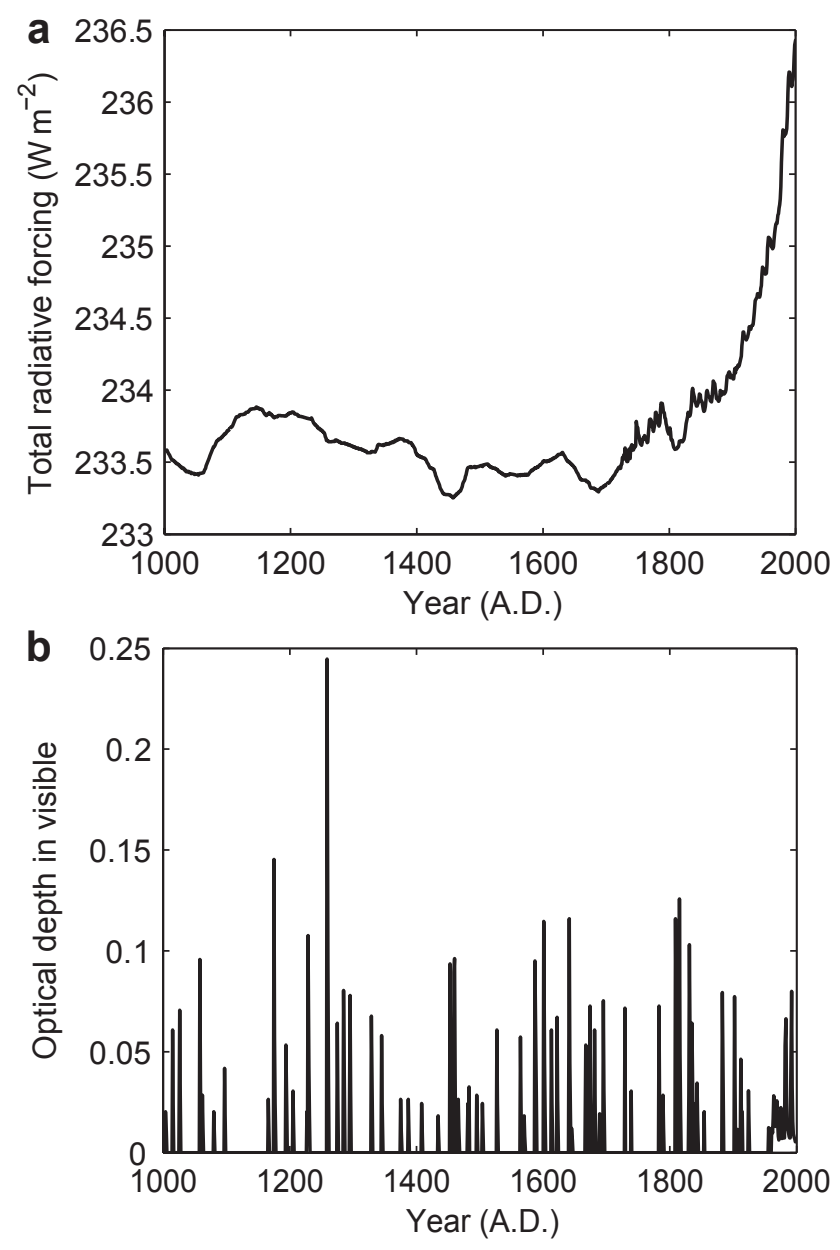

Fig. 1. Forcing from 1000 to 2000 A.D.: (a) the total radiative forcing due to solar irradiance and GHGs; (b) the optical depth changes in the visible band due to volcanic aerosols. The radiative forcing is estimated according to IPCC (2001, Table 6.2) assuming an albedo of 0.31 .

Some discrepancies occur at the beginning and at the end of the millennium. The 11th century in the TRb1 simulation is 0.2 to $0.3 \mathrm{~K}$ colder than suggested by the reconstructions (similar to the results of other simulations, e.g., Servonnat et al., 2010). However, the uncertainty of the reconstructed temperatures for this period is large and the simulation result is still within the range of the reconstructions. The warming in the second half of the 20th century is significantly larger in the simulations than in the reconstructions, even though the model has only a moderate equilibrium climate sensitivity of $2.32 \mathrm{~K}$ (Kiehl et al., 2006). To further investigate this increase, the simulations are compared to the HadCRUT3v data set (Brohan et al., 2006). The ensemble mean NH temperature increase in the 20th century, calculated as the difference between the averages over the two periods 1870 to 1900 resp. 1990 to 2000 , is $1.00 \mathrm{~K}$. This is substantially higher than the $0.59 \mathrm{~K}$ in the HadCRUT3v data. The main reason 


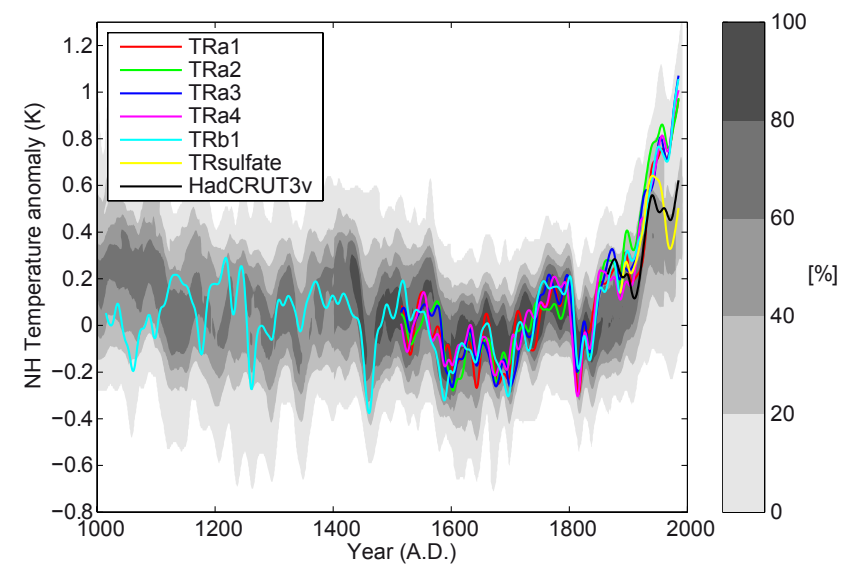

Fig. 2. Annual mean northern hemisphere SAT anomaly from all transient simulations (also including TRsulfate) compared with overlapping northern hemisphere temperature reconstructions over the last millennium (shown by grey shading; Fig. 6.13d IPCC, 2007) and the HadCRUT3v data since 1860. Temperature anomalies are derived from their 1500 to 1899 means, except for the TRsulfate simulation and the HadCRUT3v data. These two time series are adjusted to have the same mean anomaly for 1870 to 1899 A.D. as the average of the other simulations. All time series are smoothed with a Gaussian-weighted filter to remove fluctuations on time scales less than 30 years.

for the larger $\mathrm{NH}$ temperature increase in our simulations is the missing negative RF from anthropogenic sulfate aerosols. This is confirmed by the TRsulfate simulation where the NH temperature rises only by $0.46 \mathrm{~K}$ in the 20 th century.

\subsection{Atlantic meridional overturning circulation}

In all simulations the time mean Atlantic meridional overturning stream function displays an anticyclonic circulation in the top $3000 \mathrm{~m}$ associated with the North Atlantic Deep Water (NADW) and a cyclonic circulation at the bottom (Fig. 3 shows the mean state for CTRL1990). The NADW circulation consists of a strong cell that occupies the entire Atlantic up to $45^{\circ} \mathrm{N}$ and of a second, weaker cell between $50^{\circ} \mathrm{N}$ to $65^{\circ} \mathrm{N}$.

To assess the variability of the strength of the circulation, the AMOC index is defined as the maximum value of the meridional overturning stream function below $500 \mathrm{~m}$ and north of $28^{\circ} \mathrm{N}$. For the CTRL1990 simulation the mean AMOC index is $15.2 \mathrm{~Sv}$ which is a realistic overturning strength according to measurements (Cunningham et al., 2007). For the other control simulations the equilibrium mean AMOC strength cannot be reasonably determined as the simulations do not reach a sufficiently equilibrated state due to the drift (Sect. 2). The best estimate, namely the mean AMOC index of the last 100 years in the simulations prior to the detrending process, is 15.9 Sv and 14.9 Sv in CTRL1500 and in CTRL1000, respectively. The exact equilibrium val-

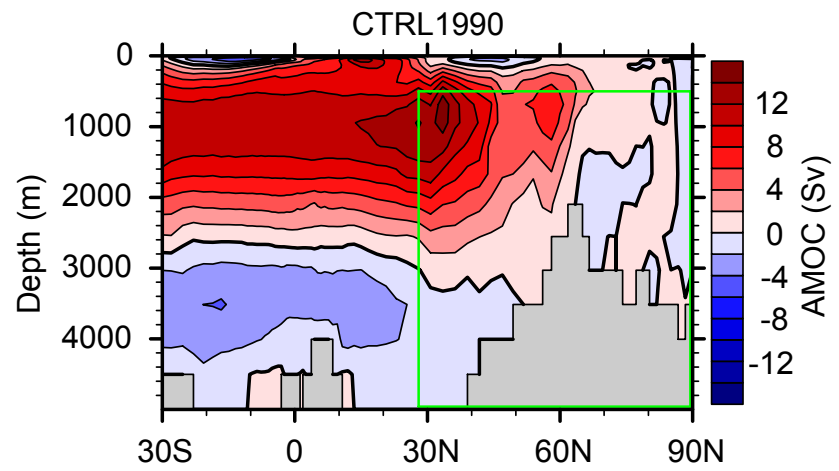

Fig. 3. The mean meridional overturning stream function for the Atlantic basin in the CTRL1990 experiment. Positive values indicate anticyclonic circulation. The AMOC index is defined as the maximum value of the stream function inside the green box $\left(28^{\circ} \mathrm{N}\right.$ to $90^{\circ} \mathrm{N}$, below of $500 \mathrm{~m}$ ).

Table 2. Standard deviations (Stdd) of the AMOC index for the annual mean, the low-pass filtered ( $>30 \mathrm{yrs}$.) and the high-pass filtered $(<30 \mathrm{yrs}$.) time series.

\begin{tabular}{lccc}
\hline Simulation & Stdd (annual) & Stdd (low-pass) & Stdd (high-pass) \\
\hline CTRL1990 & 1.09 & 0.39 & 0.94 \\
CTRL1500 & 1.09 & 0.43 & 0.93 \\
CTRL1000 & 1.09 & 0.55 & 0.88 \\
TRa1 & 1.16 & 0.53 & 0.95 \\
TRa2 & 1.29 & 0.86 & 0.88 \\
TRa3 & 1.38 & 1.05 & 0.82 \\
TRa4 & 1.37 & 0.99 & 0.88 \\
TRb1 & 1.31 & 0.87 & 0.89 \\
\hline
\end{tabular}

ues are not important in this study as the analysis focuses on the variability of the AMOC. For the analysis in the control simulations, anomalies from the average over the full simulation length are used. For the transient simulations the anomalies are calculated with respect to the mean value of the corresponding control simulation.

Table 2 shows the standard deviations (Stdd) of the AMOC index for the annual mean values and for the high-pass $(<30$ years period) and low-pass ( $>30$ years period) filtered time series. The overall variability is of similar magnitude in the three control integrations; however, the low-pass Stdd is slightly enhanced in the CTRL1000 simulation. Compared to the control integrations the annual mean AMOC index in the transient experiments exhibits enhanced variability. The increase of the variability is small (significant at the $10 \%$ level) for the TRa1 simulation, but highly significant (at the $1 \%$ level) for $\mathrm{TRa} 2$ to $\mathrm{TRa} 4$ and $\mathrm{TRb} 1$. The separation into a low and a high-frequency part reveals that the Stdd does not change in the high-frequency part, while the low-pass filtered time series show enhanced variability - except in the TRa1 simulation, where the Stdd is in the same range as in the control integrations. Note that this result is insensitive 


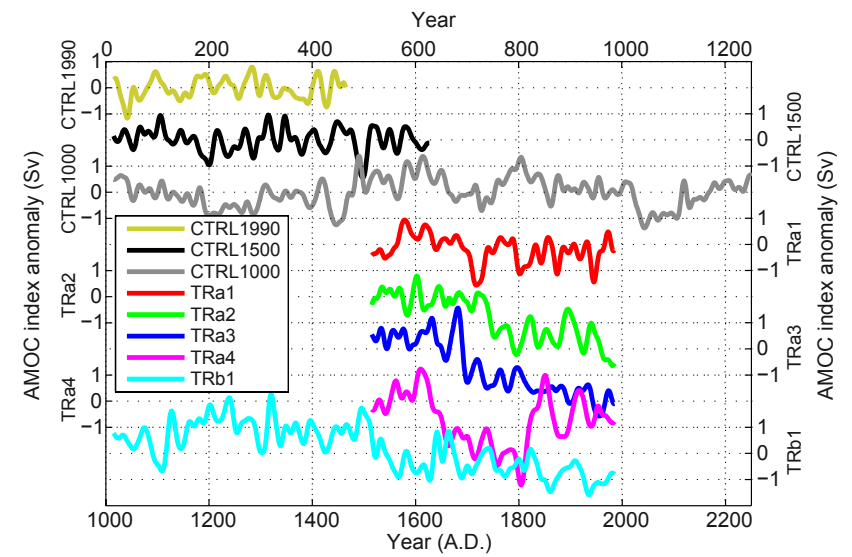

Fig. 4. Low-pass filtered time series of the AMOC index. The time series of the control integrations show the anomaly from their mean, while the time series of the transient simulations are calculated as the anomaly from the mean of the initializing control experiment. The upper abscissa indicates the model years for the control simulations and the lower abscissa corresponds to the transient simulations.

to the low-pass filter as filtering with a 10 or 50 years lowpass reveals similar differences between control and transient simulations.

The different behavior of the control and transient simulations is also evident in the low-pass filtered time series of the AMOC index (Fig. 4). In the CTRL1990, the CTRL1500, and the TRa1 experiments the AMOC index is rather stable, mostly fluctuating in a band of $\pm 1 \mathrm{~Sv}$ around zero with short periods of stronger anomalies. The time series for the CTRL1000 simulation behaves similarly, except for the model years 1020-1100 where the anomaly is in the order of $-1 \mathrm{~Sv}$. In contrast to this, the AMOC index in the other transient simulations exhibits prolonged periods of strong or weak overturning - most visible in TRa2 to TRa4 with generally high AMOC-index values from 1500-1720 (TRa2), 1500-1680 (TRa3), 1500-1620 and 1830-2000 (TRa4) and low values from 1750-2000 (TRa2), 1700-2000 (TRa3) and 1650-1810 (TRa4) - leading to the increased low-frequency variability (Table 2 ).

To identify the transitions between periods of strong and weak AMOC the ramp function regression method is applied to the time series (Mudelsee, 2000). The method calculates the least-square fit to a time series, that consists of two levels and a linear ramp in the middle. We apply the method to the annual mean AMOC index using running windows of 51, 101 and 201 years. The focus is set on significant and persistent changes of the mean AMOC. Thus, we consider only ramps (i.e., transitions), where the two levels are separated by more than one Stdd of the AMOC index in the control simulations (1.09 Sv) and where each level extends to a period of at least 20 years (i.e., the ramp can not be in the first and last 20 years of the running window).

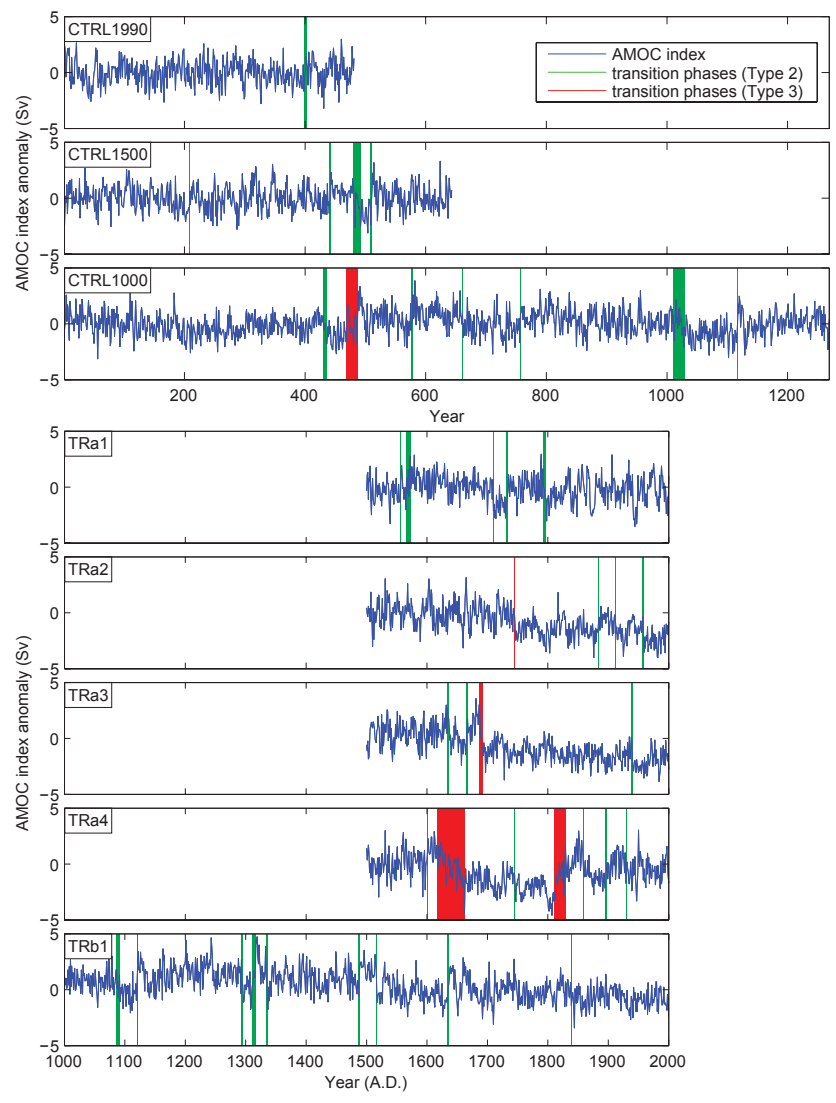

Fig. 5. Annual mean AMOC index anomaly time series and the transition phases identified by the ramp function regression analysis described in the text. The transitions are grouped into Type 2 (green) and Type 3 (red). The two Types are defined according to the characteristics of the AMOC difference pattern (see Fig. 6). The width of the colored bars indicates the duration of the linear transition from stronger to weaker AMOC (and vice versa).

The transitions that meet these two conditions at least once for any of the three running windows are presented in Fig. 5. Each transition phase indicates the period from the start to the end of the ramp. In the case of differing start and end years for the same transition, the transition phase covers the period from the earliest start to the latest endpoint. The prolonged periods of strong and weak overturning that have been estimated by eye in Fig. 4 are indeed separated by transitions. However, the applied method identifies many additional transitions. Most of the transition phases are relatively short (less than 5 years) and only in a few cases the duration exceeds 10 years. Generally, we find more transitions in the transient simulations than in the control simulations. The quantity alone though cannot fully explain the increased variability, e.g., we find more transitions in the TRa1 simulation than in TRa2 and TRa3.

We further analyze the transitions by investigating the structural changes of the AMOC. Therefore, difference patterns between the weak and strong AMOC state are 
evaluated. For the two states we use the mean of the periods directly before and after the transitions - both with a length of 20 or 100 years. The resulting patterns are compared to two composite patterns which focus either on high-frequency or on low-frequency variations. The two composite patterns are calculated as the difference between the negative composite (all years where the AMOC index is more than one Stdd lower than the mean) and the positive composite in the CTRL1990 simulation. The only difference is that for the first pattern (high-frequency) the annual mean AMOC index is used to determine the composite, whereas for the second pattern (low-frequency) the low-pass filtered values are used.

For the high-frequency composite pattern (Type 1; Fig. 6a), the largest differences are found at $30^{\circ} \mathrm{N}$ to $35^{\circ} \mathrm{N}$ extending to the deep ocean and with opposite sign between $50^{\circ} \mathrm{N}$ to $60^{\circ} \mathrm{N}$, i.e., a low AMOC index corresponds to a reduced circulation in the main overturning cell and an increased circulation in the high latitudes. Also for the lowfrequency composite pattern (Type 2; Fig. 6b), the strongest changes are found at $30^{\circ} \mathrm{N}$ to $35^{\circ} \mathrm{N}$, but the amplitude is reduced compared to the Type 1 pattern. The anomaly is uniformly distributed over wide areas of the Atlantic except for some parts of the deep ocean and north of $75^{\circ} \mathrm{N}$. Thus, for this Type the changes in the AMOC index correspond to a much broader weakening or strengthening of the overturning circulation.

Patterns that are very similar to the low-frequency composite result are also found for most of the transitions using the 20-year periods (Fig. 6c). The mean difference pattern for these transitions, which are indicated as Type 2 in Fig. 5, exhibits the same structure as the low-frequency pattern except for some minor differences in the mid-latitude deep ocean. Due to the high pattern-correlation coefficient of 0.94 (in the North Atlantic $10^{\circ} \mathrm{N}$ to $60^{\circ} \mathrm{N}$, below of $500 \mathrm{~m}$ ) between the two patterns, both cases are considered as Type 2 patterns. Using the 100-year periods, most of the Type 2 difference patterns no longer show significant changes suggesting that the identified pattern corresponds to multidecadal variations of the AMOC (not shown).

Six of the transition patterns reveal a rather different structure, which is found for the 20-year periods and even more clearly for the 100-year periods (Type 3; Fig. 6d). These transitions are indicated as Type 3 in Fig. 5. The difference pattern displays a strong negative anomaly in the mid-latitudes. The largest anomalies appear at the northern boundary of the main overturning cell between $40^{\circ} \mathrm{N}$ to $45^{\circ} \mathrm{N}$. Thus, in contrast to the Type 1 and 2 patterns, the maximum differences are not located at the center of the main overturning cell. The structure of the differences leads to a southward shift of the maximum of the meridional overturning circulation from $34^{\circ} \mathrm{N}$ to $28^{\circ} \mathrm{N}$. Apart from the negative anomalies between $20^{\circ} \mathrm{N}$ to $45^{\circ} \mathrm{N}$ the changes are weak and with either sign. Note that the mean difference pattern is a good representation of the individual Type 3 transitions (pattern correlation coefficients vary between 0.88 to 0.98 ), but the amplitude
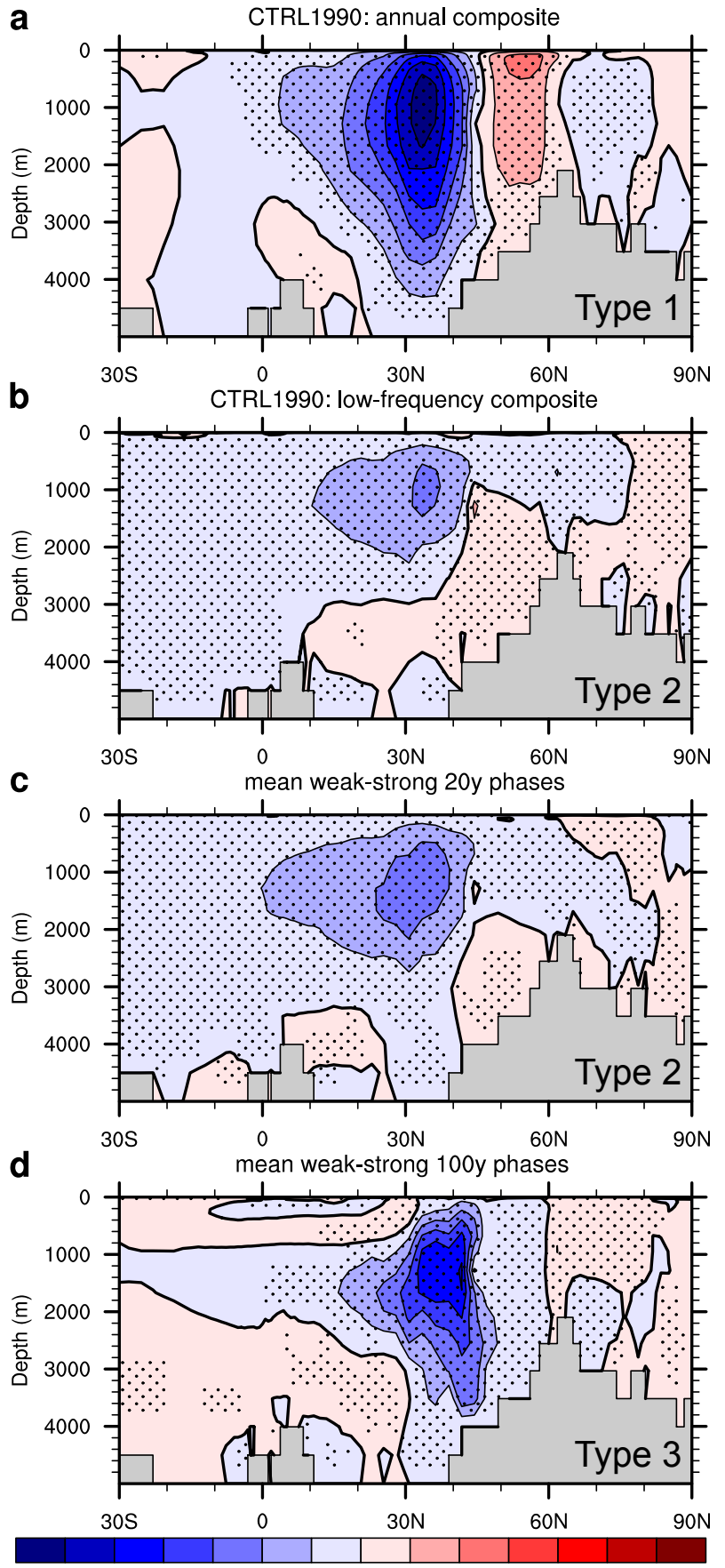

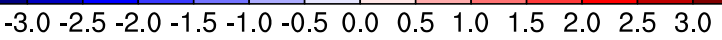
AMOC anomalv (Sv)

Fig. 6. The mean variability pattern of the AMOC: (a) difference between the composite of all years where the annual AMOC index is at least one Stdd below the mean and the composite of all years where it exceeds the mean by one Stdd for the CTRL1990 simulation (Type 1), (b) as (a) but using the low-pass filtered time series to determine the composite (Type 2), (c) mean difference pattern of the weak and the strong AMOC phases (using 20 year periods prior to and after the transition) averaged over all Type 2 transitions indicated in Fig. 5, (d) as (c) for the Type 3 transitions and using 100 years periods to reduced the impact of noise. The stippled areas are significant at the $5 \%$ level based on the two-sided Student's t-test. 
is reduced for the CTRL1000 and the TRb1 transition. The low values of the pattern correlation coefficients with Type 1 (0.62) and Type $2(0.45-0.54)$ highlight the different structure of the Type 3 pattern.

In summary, the Type 1 and Type 2 transitions show a general change of strength in the main overturning cell on time scales of years to several decades. These variations of the overturning strength are present in both control integrations and transient experiments. The Type 3 transitions show not only a persistent change of the AMOC strength but also the structure of the AMOC is changed. Furthermore, Type 3 transitions occur significantly (at the 5\% level) more frequently in transient simulations: In a total of 3000 years we find five such transitions compared to just one in the 2400 years of control integrations. Thus, these Type 3 transitions are exceptional and we concentrate our analysis in the following on this Type.

\subsection{Linear AMOC response to the forcing}

The more frequent Type 3 transitions in transient simulations suggest an impact of the time-varying forcing on the transition process. However, the timing of the transitions is different in the transient simulations ranging from the early 12th (TRb1) to the early 19th century (TRa4). To investigate the link between the AMOC transitions and the external forcing, we analyse the linear impact of the time-varying forcing on the AMOC. Based on the typical time scale of variations, the different forcing mechanisms are subdivided in two categories: the slowly changing RF (Fig. 1a) and the fast-varying volcanic forcing (Fig. 1b).

Comparing the RF time series and the AMOC index in the transient simulations, a linear impact of the RF on the AMOC can be excluded. Strong variations in the mean AMOC strength occur in periods of low RF changes, while the strong and mainly anthropogenic increase of the RF in the 20th century does not produce a response in the AMOC index. Also in the time periods without a transition, the AMOC and the RF are not correlated from 1000 to 2000 A.D. (not shown).

The linear impact of the volcanic forcing on the AMOC is estimated using the time period 1500 to 2000 A.D. and considering eruptions that reduce the optical depth of the atmosphere in the visible band by at least 0.05 . Thus, the 21 strongest eruptions are used. For each event we define a reference period and we calculate the anomaly to the mean of this period. Generally, the reference period consists of the five years prior to an eruption. If volcanoes erupt in succession, the reference period is shortened to assure a minimum gap of three years between an eruption and the start of the reference period for the next one. In cases where this is not possible the anomalies are calculated to the reference period of the first eruption for both events. To filter out interannual fluctuations the response is averaged over five-year periods for the 20 years following an eruption. As the volcanic aerosol distribution in TRb1 differs from the one in the TRa simulations, the TRb simulation is examined separately. In both cases, the analysis shows no significant response of the AMOC index to the volcanic forcing for any of the five-year periods (therefore not shown).

\subsection{Type 3 transitions}

\subsubsection{Mean changes in the ocean}

The Type 3 transitions in the AMOC are accompanied by rather strong changes in other ocean quantities. To evaluate the differences we use the same 100 -year periods prior and after the transitions that have been used for the overturning. As the general characteristics of the pattern are identical for all six transitions the mean difference over all transitions is presented. To determine the significance of the differences the mean for all simulations is adjusted so that the mean value during the strong AMOC period is the same, the strong AMOC periods (and similarly the weak AMOC periods) are concatenated and the two-sided Student's t-test at $5 \%$ level is applied at every grid point for the resulting two time series.

The barotropic stream function (BSF) - the vertically integrated horizontal circulation - consists in the North Atlantic of a anticyclonic circulating subtropical gyre and a cyclonic circulating subpolar gyre. The BSF difference pattern is significant in almost the entire North Atlantic (Fig. 7a). In the weak AMOC state the transport is reduced in both gyres. The largest differences are found between $30^{\circ} \mathrm{N}$ and $50^{\circ} \mathrm{N}$ which is consistent with the changes in the overturning circulation. Apart from the weakening the BSF exhibits a northward shift of the zero contour line between the two gyres (subtropicalsubpolar gyre boundary) in the central North Atlantic. Note, however, that this northward extension of the subtropical gyre is not a consistent feature for all ocean levels, but is mainly dominated by circulation changes in the deep ocean. In the upper $500 \mathrm{~m}$ the circulation exhibits a more southward flow in this region (not shown).

A second ocean quantity that is important for the AMOC is the deep convection in the Northern Atlantic and the surrounding seas. The main deep-water formation (DWF) sites, as indicated by the mixed-layer depth (MLD), are in the central GIN Seas along the ice edge, in the Irminger Sea and in the passage from the Labrador Sea into the North Atlantic (Fig. 7b). Interestingly, the difference pattern displays a dipole, with less vigorous convection in most regions of the western DWF sites and increased convection in the GIN Seas and between Iceland and Scotland. This is in contrast to the Type 2 pattern where the MLD is lowered at all DWF sites (not shown).

The difference patterns for the sea ice cover and for the sea surface density in the deep convection sites correspond to the changes in the MLD (Fig. 7c,d). In the Labrador and Irminger Seas the ice edge extends further south and the sea surface density is reduced, while in the GIN Seas the sea ice 
a

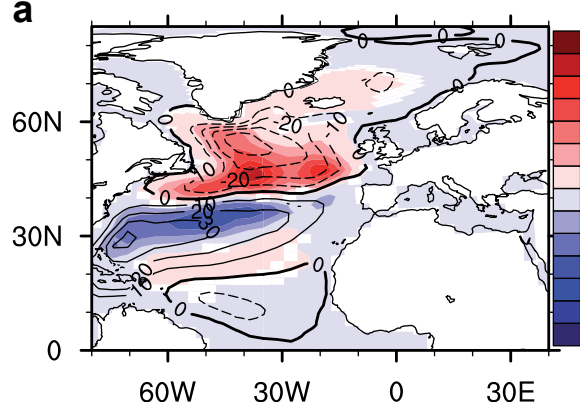

C
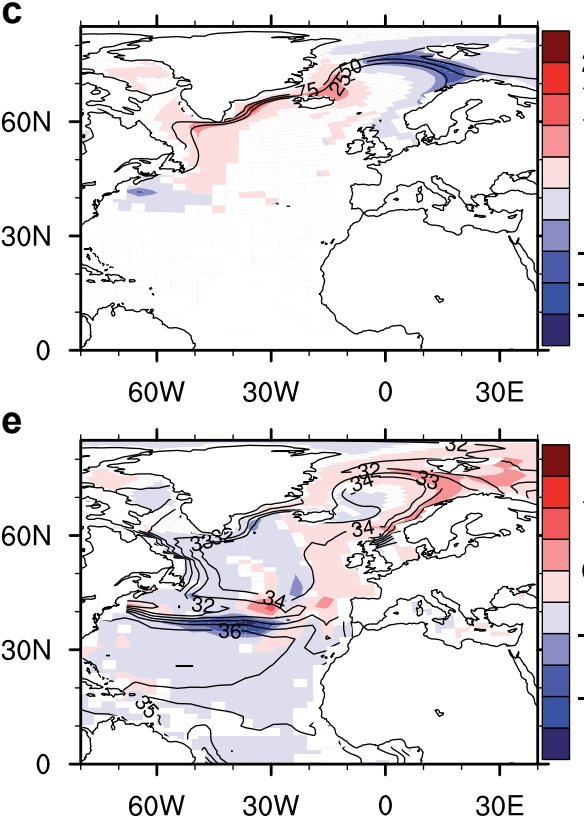

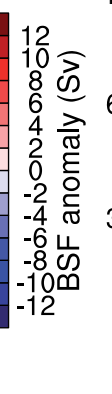

b
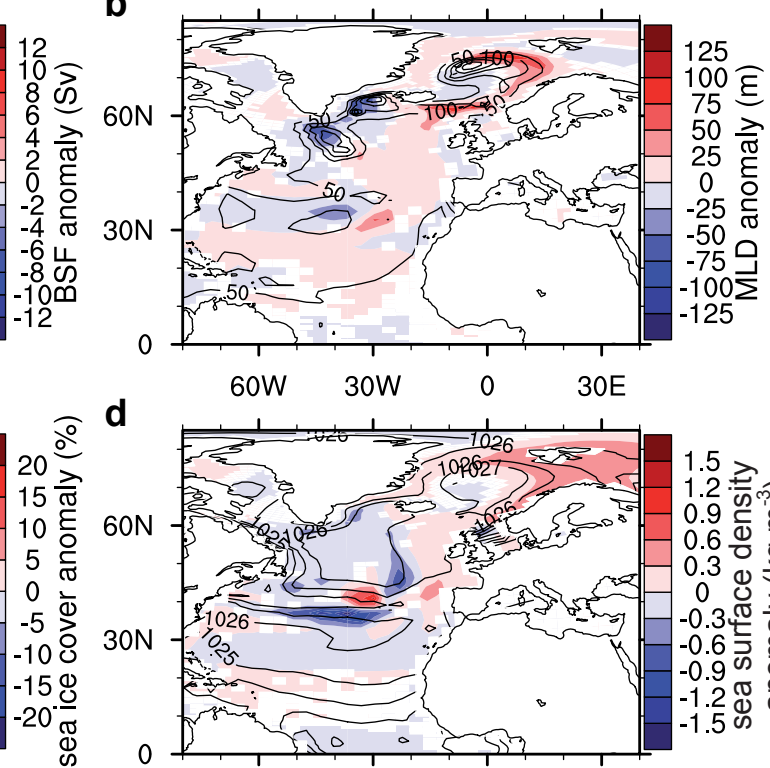

d

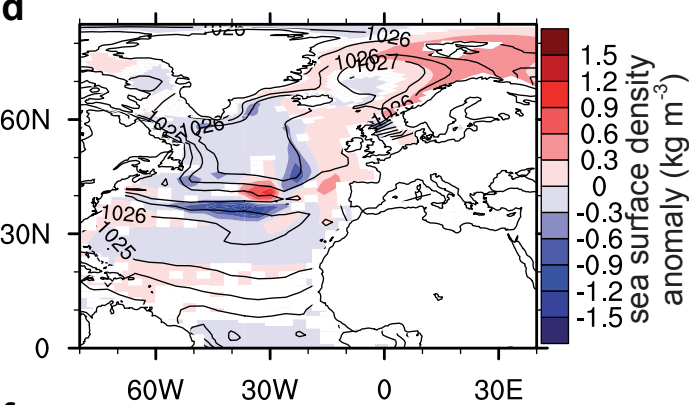

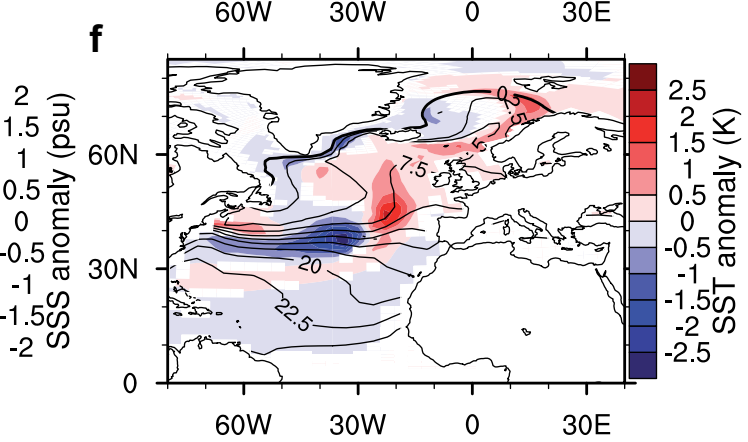

Fig. 7. The difference of the weak and strong AMOC periods (colors) and the mean state for the weak AMOC (black contour lines) in the North Atlantic region averaged over all Type 3 transitions: (a) barotropic stream function (BSF), (b) mixed layer depth (MLD), (c) sea ice cover, (d) sea surface density, (e) sea surface salinity (SSS), and (f) sea surface temperature (SST). For the difference patterns only the areas are colored that are significant at the 5\% level based on the two-sided Student's t-test. For the contour lines the intervals are 10 Sv (BSF), $50 \mathrm{~m}$ (MLD), $25 \%$ (sea ice cover), $1 \mathrm{kgm}^{-3}$ (sea surface density), $1 \mathrm{psu}$ (SSS), and $2.5 \mathrm{~K}$ (SST), respectively.

cover is decreased and the sea surface density is increased. The largest differences in the sea surface density are found along the NAC. The pattern displays mostly negative values - reaching $-1.5 \mathrm{kgm}^{-3}$ in a longitudinal band at $37^{\circ} \mathrm{N}-\mathrm{ex}-$ cept in a small area at $40^{\circ} \mathrm{N}$ and $30^{\circ} \mathrm{W}$. The large density differences in the mid-latitudes are likely due to a slightly changed path of the NAC. In the weak AMOC state the eastward flow of the NAC at the surface is displaced southward in the central Atlantic. Because the latitudinal density gradient in this region is large (Fig. 7d) small changes of the path result in strong differences of the density.

The main contribution to the strong sea surface density changes arises from salinity changes rather than from temperature changes. This is obvious from the similarities between the density and the salinity patterns (Fig. 7d,e) and the differences compared to the sea surface temperature (SST) pattern (Fig. 7f). It is also confirmed by the analysis of the temperature and salinity contributions to the density changes (not shown). In the DWF regions the SST and the salinity changes contribute with opposite signs to the density. There, the SST is strongly affected by the convection: on its way to the North the warm water from the tropics transfers heat to the atmosphere and the surface cools so that the water column exhibits a reversed temperature gradient with a cold top layer (roughly the top $50 \mathrm{~m}$ ) and warmer water below. In the convection regions this type of stratification produces a temperature response at the surface based on the rate of mixing. Increased (decreased) mixing leads to higher (lower) SSTs, as more (less) heat is convected from the deep ocean to the surface. So the positive SST differences at the IcelandScotland ridge and along the Scandinavian coast up to Spitsbergen are an effect of the increased mixing in these regions, as well as the negative SST differences in the Irminger Sea and South of Greenland are caused by a reduced convective activity. 

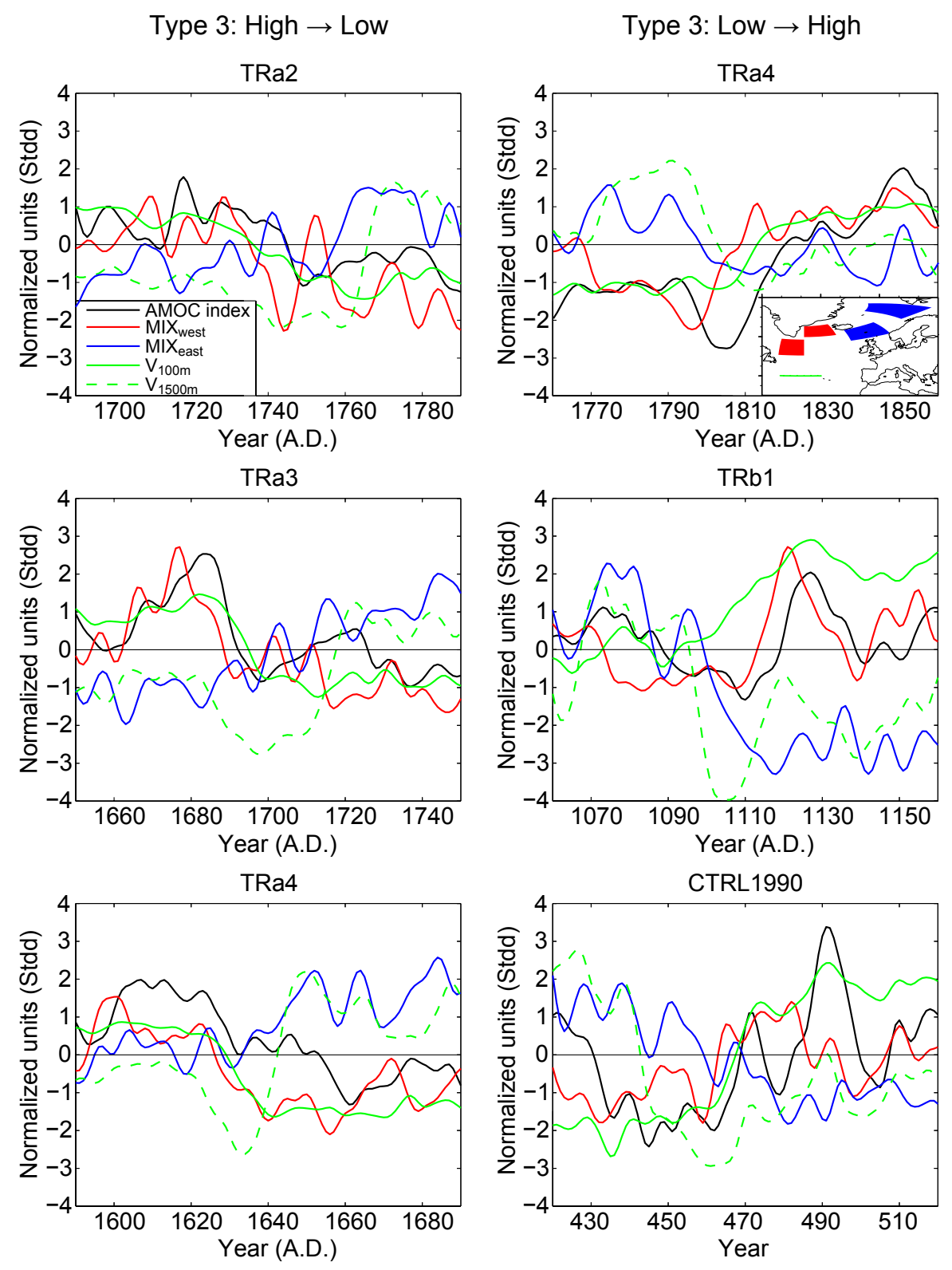

Fig. 8. Low-pass filtered and normalized time series of the AMOC index, the mixed layer depth averaged over the westerly (MIX $\mathrm{west})$ and easterly $\left(\mathrm{MIX}_{\text {east }}\right)$ DWF regions and the mean velocity across the boundary between the two gyres for the top $100 \mathrm{~m}\left(\mathrm{~V}_{100 \mathrm{~m}}\right)$ and for a mean depth of $1500 \mathrm{~m}\left(\mathrm{~V}_{1500 \mathrm{~m}}\right)$. The areas that are used for the calculation are indicated in the figure (the color of the time series corresponds to the color of the areas). Note that the applied low-pass filter is different to Fig. 2 and removes variations on time scales less than 10 years. The left column shows the Type 3 transitions from a high to a low AMOC index and the right column the transitions from low to high.

The oceanic changes - especially SST changes - that go along with a Type 3 transition should also be present in marine proxy reconstructions of the last millennium. To investigate this, two SST reconstructions from the Norwegian Coast (Kristensen et al., 2004, core P1-003MC) and from the North of Iceland (Sicre et al., 2008) with high temporal resolutions of several years to a few decades are used. The record from Kristensen et al. (2004) exhibits multidecadal variations, but no prolonged periods with different mean SSTs are found since 1400 A.D. In the longer reconstruction of
Sicre et al. (2008), however, the period from $\sim 980$ to $\sim 1350$ A.D. is roughly $1 \mathrm{~K}$ warmer than before and after this time, and the transitions from low to high SST (and vice versa) occur within a few decades. Thus, even though the investigated proxy data are not sufficient to provide clear evidence for the occurrence of SST changes that corresponds to an AMOC transition, the record of Sicre et al. (2008) suggests that strong and persistent changes of regional SSTs might have happened in the past. 


\subsubsection{Time behavior}

So far it is not clear whether the Type 3 transitions are a consequence or the cause of the changes that have been discussed above. Thus, we define several additional indices (apart from the AMOC index) to analyse the temporal evolution of the Type 3 transitions individually. Two indices track

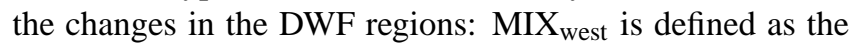
area-mean MLD in the Irminger Sea and south of Greenland, and MIX $_{\text {east }}$ corresponds to the average MLD in parts of the GIN Sea and at the Iceland-Scotland ridge (see inset of Fig. 8 for the exact regions). Variations in these MLD indices are mostly caused by salinity - and therefore density - changes in the top layers of the ocean (not shown). Another two indices measure the mean meridional velocity at the boundary between the subtropical and subpolar gyres $\left(50^{\circ} \mathrm{W}-30^{\circ} \mathrm{W}\right.$, $\left.40^{\circ} \mathrm{N}\right)$ tracking changes in the top $100 \mathrm{~m}\left(\mathrm{~V}_{100 \mathrm{~m}}\right)$ and at a mean depth of $1500 \mathrm{~m}\left(\mathrm{~V}_{1500 \mathrm{~m}}\right)$.

100-year segments of the low-pass filtered time series of these five indices (normalized and centered around the Type 3 transition periods) are shown in Fig. 8. Note that for these time series the Gaussian-weighted low-pass filter removes fluctuations on time scales of less than 10 years. The sequence of the changes varies between the individual transitions, but there is some agreement for the transitions from strong to weak AMOC (TRa2, TRa3 and the first in TRa4) and for the transitions from weak to strong AMOC (the second in TRa4, TRb1 and CTRL1000). In the case of a transition from strong to weak AMOC the process is led by a

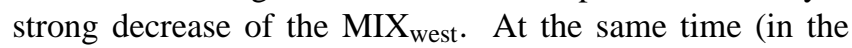
$\mathrm{TRa} 3$ simulation delayed by a few years) both $\mathrm{V}$ indices start to decrease as well, and 5 to 10 years after the MIX $\mathrm{X}_{\text {west }}$ index, the AMOC weakens. Simultaneously with these changes, the MIX $_{\text {east }}$ exhibits an unsteady increase lasting for several decades. 15 to 40 years after the initial MIX west changes roughly at the time when MIX $_{\text {east }}$ reached its new level -, $\mathrm{V}_{1500 \mathrm{~m}}$ shifts from strong negative to strong positive values completing the transition.

The transitions from weak to strong overturning show a different sequence of the changes. At first, MIX $_{\text {east }}$ starts to decrease and $\mathrm{V}_{1500 \mathrm{~m}}$ switches from positive to negative values. 10 to 20 years after these changes, the MIX west $_{\text {index }}$ increases and another 5 to 10 years later the AMOC strengthens. The evolution of $\mathrm{V}_{100 \mathrm{~m}}$ is less clear, as in TRa4 and CTRL1000, $\mathrm{V}_{100 \mathrm{~m}}$ changes simultaneously to the AMOC index, whereas in TRb1 it already starts to decrease with the initial MIX east $_{\text {change. }}$

For a better understanding of these changes, our results are compared with mechanisms that are responsible for the AMOC variations of Type 1 and 2 . The high-frequency variability of the AMOC (Type 1) is mainly caused by changes in the atmospheric wind stress forcing (not shown). In contrast to the Type 1 transitions, no anomalous wind stress forcing is detected for the low-frequency variations (Type 2 and 3) of the AMOC (not shown).
To analyse the mechanisms for the type 2 transitions we perform a lag-correlation analysis for the three simulations without Type 3 transitions using the low-pass filtered index time series. For these simulations, the AMOC index exhibits the highest correlation coefficients (significant at the $1 \%$ level) with MIX $_{\text {west }}$ lagging the mixing by 4 to 5 years, whereas for MIX $\mathrm{Xast}_{\text {no }}$ nognificant correlation is found. The changes in the mixing are caused by salinity changes rather than temperature (similar to the results of D'Orgeville and Peltier (2009) for the low-resolution CCSM3, but contradicting Danabasoglu (2008) for the high-resolution CCSM3). The two velocity indices are both positively correlated (significant at the $1 \%$ level) with the AMOC. $\mathrm{V}_{100 \mathrm{~m}}$ simultaneously varies with the AMOC and $\mathrm{V}_{1500 \mathrm{~m}}$ leads the AMOC by 3 to 4 years.

Comparing these results with the Type 3 transitions, we find that the changes in MIX $\mathrm{west}_{\text {and }}$ in the velocity indices are a general feature of any low-frequency AMOC variation, even though they are exceptionally strong for the Type 3 transitions. The main differences that separate the Type 3 transitions from the Type 2 variations are the coupling of the MLD in the eastern convection regions and the strong change of $\mathrm{V}_{1500 \mathrm{~m}}$ which evolves opposite to the AMOC index. Thereby, the coupling of the MIX east $_{\text {with the AMOC is }}$ likely connected to the changes in the gyre circulation. During the weak AMOC state, the Atlantic inflow into the GIN Seas exhibits an increased density in the top $200-300 \mathrm{~m}$ and a lower density below compared to the strong AMOC state (not shown).

In summary, the Type 3 transitions of the AMOC can be triggered by strong salinity anomalies in the deep water formation sites.

\subsubsection{Atmospheric response}

The changes in the ocean directly impact the atmosphere, especially SAT and precipitation. We use two independent methods to isolate the atmospheric response of the Type 3 transitions: (i) the linear effect of the external forcing on the atmosphere is removed and the difference between the mean of weak and strong AMOC periods is calculated, and (ii) the difference between a weak AMOC period in one simulation and the same period in a similar simulation with a strong AMOC is calculated. Weak and strong AMOC states are again defined by the 100 -year periods prior and after the transitions. A detailed description of the two methods can be found in the appendix. The overall pattern is similar for both methods, therefore only results of the first method are shown here.

The SAT response in the North Atlantic is presented in Fig. 9a. Note that positive values correspond to warmer conditions in the weak AMOC period and that only grid points that are statistically significant at the 5\% level based on the two-sided Student's t-test are colored. Over the ocean, the SAT pattern resembles the SST pattern in Fig. 7d. There 

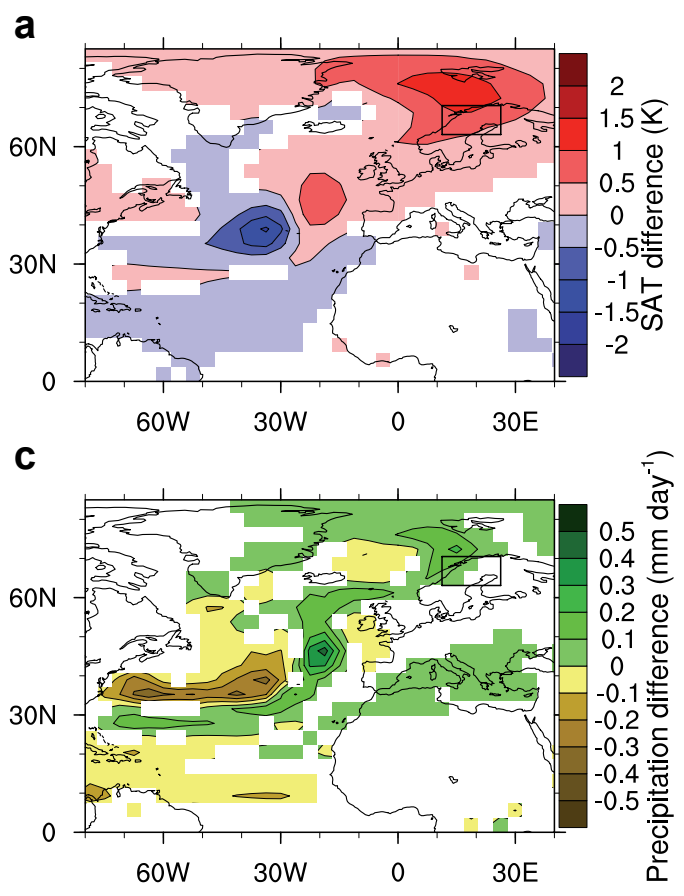

b
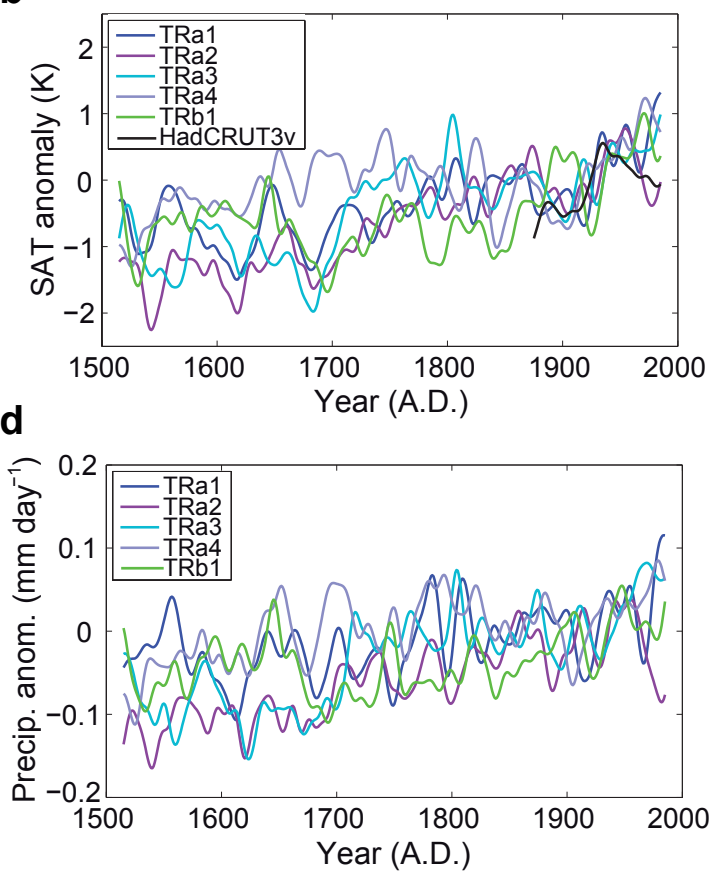

Fig. 9. The atmospheric response due to the changed ocean circulation in Type 3 transitions: (a) SAT difference pattern of the weak versus the strong AMOC state after the linear effect of the forcing has been removed (first method). Only the values that are statistically significant at the 5\% level based on the two-sided Student's t-test are colored. (b) low-pass filtered time series of the SAT averaged over the black box $\left(63^{\circ} \mathrm{N}-70^{\circ} \mathrm{N}, 11^{\circ} \mathrm{E}-26^{\circ} \mathrm{E}\right)$ in figure (a) for all transient simulations. Additionally, the mean temperature for Northern Scandinavia according to the HadCRUT3v data is shown. The time series show anomalies with respect to the mean of the period 1900-1950 A.D. (c) and (d) as (a) and (b) for precipitation.

is a strong negative anomaly in the central North Atlantic and some minor SAT reductions emerge in the Labrador Sea and at the Southeastern coast of Greenland. The positive anomalies are located near Newfoundland, in the eastern North Atlantic and in the GIN Seas; the largest amplitudes in the order of $1.25 \mathrm{~K}$ are found in the Norwegian Sea south of Spitsbergen. The SAT response over land is generally weaker. The only exceptions are the areas near the GIN Seas in particular Scandinavia where temperature differences exceed $0.5 \mathrm{~K}$. This region is of special interest for comparison with reconstructions, as it is the origin of several proxy time series reconstructing past climate conditions (e.g., Briffa et al., 1992; Helama et al., 2009; Büntgen et al., 2011).

To better evaluate the impact of the ocean circulation change on the Scandinavian temperature in comparison with other sources of variability, a regional average is calculated $\left(63^{\circ} \mathrm{N}-70^{\circ} \mathrm{N}, 11^{\circ} \mathrm{E}-26^{\circ} \mathrm{E}\right.$; box in Fig. 9a). Note that for this calculation the linearly estimated effect of the forcing is not removed. The low-pass filtered time series for the transient simulations and - for the period 1860-2000 A.D. - for the HadCRUT3v data, which has also been averaged over Northern Scandinavia, are shown in Fig. 9b. The time series exhibit a large spread between the simulations and also compared to the measured temperature indicating a high level of internal variability. Nevertheless, the periods of a weak overturning generally coincide with high Scandinavian temperature, e.g., 1650 to 1800 A.D. in TRa4. The mean difference between the weak and strong AMOC periods is $0.63 \mathrm{~K}(0.61 \mathrm{~K}$ after removing the linear effect of the forcing) and exceeds one standard deviation of the low-pass filtered time series. Thus, we conclude that in our simulations the Type 3 transitions are one of the main sources of low-frequency variability for the North-Scandinavian SAT for the last millennium.

This is consistent with a recent tree-ring reconstruction for northern Scandinavia which shows that for the last 500 years the summer SAT in this region is dominated by processes that are not related to the external forcing (Büntgen et al., 2011). The Type 3 transitions that have been found in this study demonstrate a potential mechanism that contributes to Scandinavian temperature variability and that could explain the poor representation of the external forcing signal in the Scandinavian temperature proxies. Note, however, that the tree-ring reconstruction provides results for summer temperature only.

The precipitation response to the ocean forcing, which is calculated similar to the SAT response, is mainly focused on the regions of strong SST changes (Fig. 9c). Generally, the impact is straightforward and local as in the regions with positive (negative) SST anomalies the precipitation is increased (decreased) due to increased (decreased) 

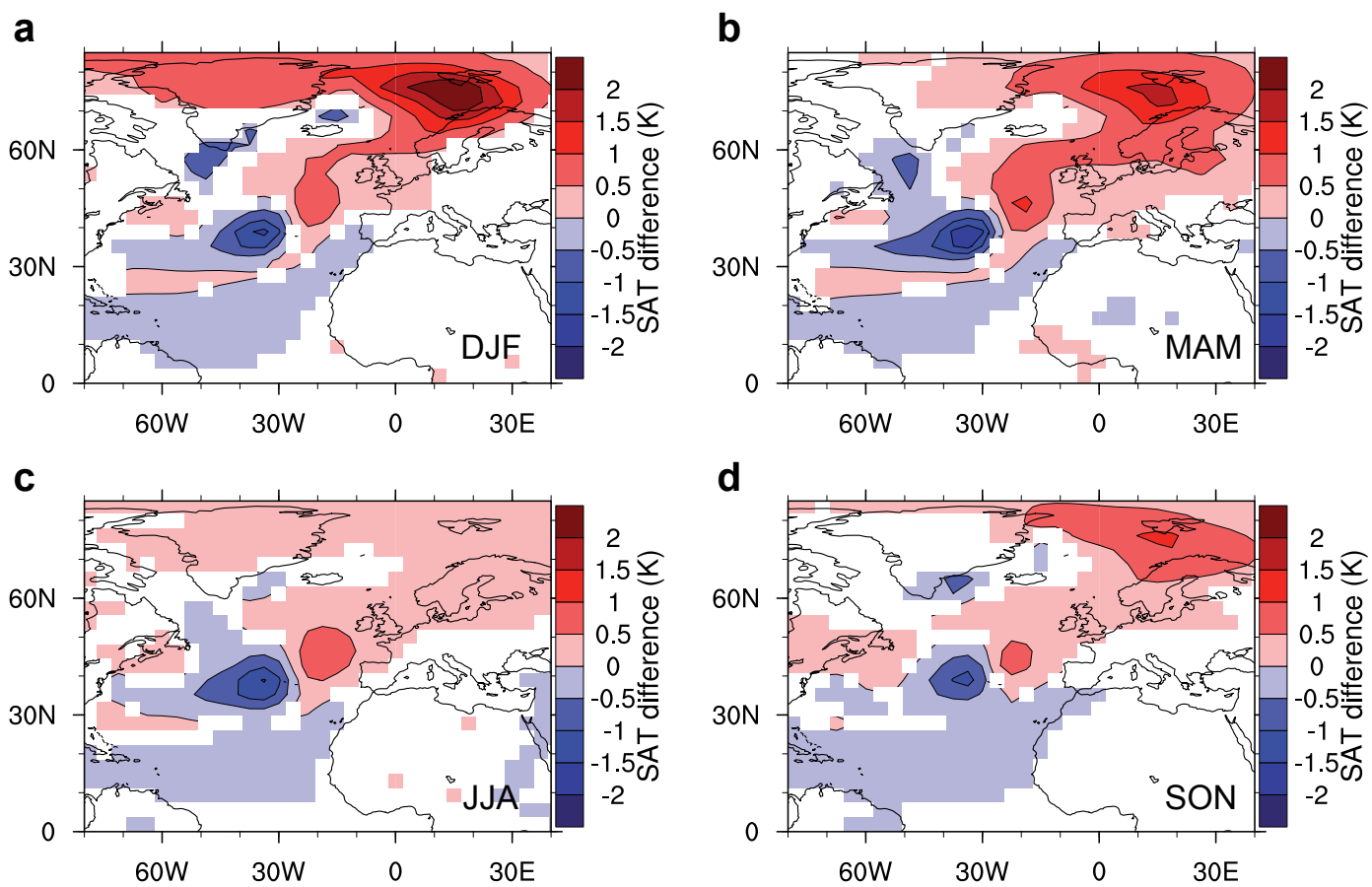

Fig. 10. Seasonal SAT response for the Type 3 transitions according to the first method: (a) winter (DJF), (b) spring (MAM), (c) summer (JJA), (d) autumn (SON). Only the values that are statistically significant at the 5\% level based on the two-sided Student's t-test are colored.

evaporation. Additionally, weak positive precipitation anomalies are found over parts of Greenland and in the Mediterranean region.

Also for the precipitation we calculate the time series over northern Scandinavia (Fig. 9d). As suggested by the spatially less extended significant precipitation response in this region, the signal of the circulation change is weaker than for the SAT and can hardly be distinguished from other sources of variability. For some of the individual Type 3 transitions, the precipitation in the weak and the strong AMOC periods is not statistically different (at the 5\% level) and overall the difference is only $0.035 \mathrm{~mm} \mathrm{day}^{-1}$. Thus, a clear impact of the transitions on the precipitation in northern Scandinavia cannot be detected, even though there is a tendency towards an increase in the weak AMOC state.

The SSTs and consequently also the atmospheric response to the SST forcing exhibit a strong seasonal cycle especially at the DWF sites. As explained in Sect. 3.4.1, the SST in the convection region is strongly coupled to the rate of the mixing. The convection in the northern high latitudes is strong in winter (December-January-February) and early spring and weak during the summer (June-July-August) producing the strongest SST differences between the periods of strong and weak AMOC in the winter (not shown). Thus, we show the seasonal response of the SAT to the Type 3 transitions (Fig. 10). The dipole pattern in the central North Atlantic is rather stable for the entire year, whereas the response in the GIN Seas ranges from more than $2 \mathrm{~K}$ in the winter to less than $0.5 \mathrm{~K}$ in the summer. The SAT in northern Scandinavia exhibits a similar seasonal cycle as in the GIN Seas, but with a less pronounced winter maximum. Also for the precipitation the seasonal response strongly varies with the maximum amplitudes in the winter (Fig. 11). The patterns are similar for all seasons except summer, where no clear response is found. In the Scandinavian region, however, the slight increase of the precipitation is uniform throughout the year.

\section{Summary and discussion}

The AMOC variability is investigated in several control and transient simulations that are performed using the lowresolution version of the CCSM3. The simulated NH temperature evolution is consistent with reconstructions for most of the last millennium and the simulations exhibit a realistic overturning strength. A shortcoming in the setup of the transient simulations in the late 20th century is the missing timevariable sulfate aerosols, which results in an unrealistically strong temperature increase in the 20th century.

We find that the Stdd of the AMOC index is significantly larger in the transient simulations than in the control simulations. The Stdd difference is mainly caused by lowfrequency variations that lead to a persistent change of the mean index values and that are associated with structural changes in the AMOC pattern (Type 3 transitions). As these rare transitions occur significantly more frequently (at the $5 \%$ 
a

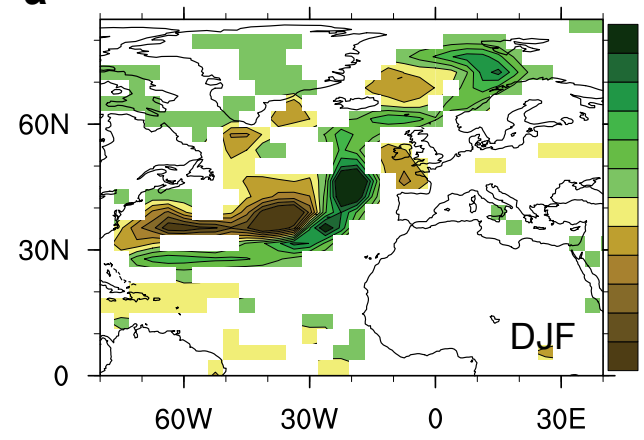

C
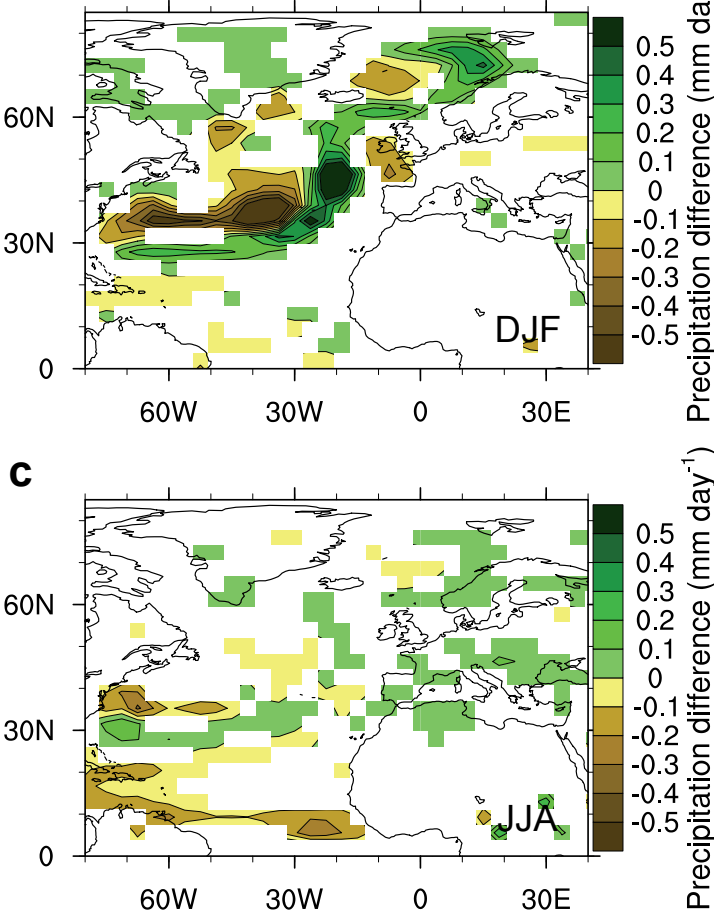

b

(

d

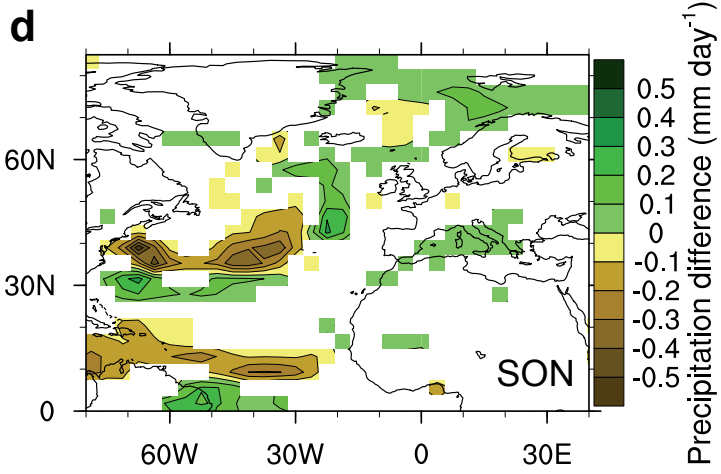

Fig. 11. Seasonal precipitation response for the Type 3 transitions according to the first method: (a) winter (DJF), (b) spring (MAM), (c) summer (JJA), (d) autumn (SON). Only the values that are statistically significant at the 5\% level based on the two-sided Student's t-test are colored.

level) in the transient simulations, we conclude that the transient forcing induces and supports such variations. A possible explanation for this behavior might be that the forcing increases the internal ocean variability, so that conditions which are needed to initiate a Type 3 transition are more likely to occur in transient simulations.

In agreement with this speculative statement, the impact of the time-varying forcing on the AMOC is not linear. For the volcanic forcing, we find no significant response of the overturning circulation at all, in contrast to Stenchikov et al. (2009). A possibility for this difference could be shortcomings of the representation of the dynamical response in the atmosphere to volcanic aerosols in the CCSM3 (Stenchikov et al., 2006), which are also found in our simulations (not shown). As for the volcanic forcing, there is no clear relationship between the RF variations and the AMOC intensity in our simulations. Other studies report a negative impact of strong RF changes on the AMOC, both for changes of the solar irradiance (e.g., Goosse and Renssen, 2006) and GHGs (e.g., Bryan et al., 2006). However, this generally applies to RF changes that are stronger than the ones during the last millennium. Extending our transient simulations to the 21 st century under the A2 scenario, a decrease of the AMOC strength of $17 \%$ is found similar to the reduction reported in Bryan et al. (2006) (not shown). Thus, we conclude that the $\mathrm{RF}$ changes in the last millennium are too weak to cause a direct AMOC response. This conclusion supports the results of Meehl et al. (2006) who found no significant impact of the forcing on the AMOC in the 20th century using a higher resolution of the CCSM3.

The analysis of the Type 3 transitions shows that the weak AMOC phases go along with a weakened horizontal barotropic ocean circulation. For the SST, SSS, sea surface density and MLD two regions are identified as main impact areas, namely the convection sites in the North Atlantic (in the present simulations they are in the GIN Seas, in the Irminger Sea and South of Greenland) and the boundary region between the subtropical and the subpolar gyres in the central North Atlantic. In the convection sites, we find an east-west dipole pattern for all investigated quantities, which is untypical for other AMOC variations. In contrast, the midocean changes mainly concern SST and SSS for which they are even stronger than in the DWF regions exceeding $2.5 \mathrm{~K}$ for the SST and 2 psu for the SSS.

Similar patterns for BSF, SST and SSS are found in D'Orgeville and Peltier (2009) for the difference between 300-year subsections of two low-resolution CCSM3 simulations (control 1870 and control 1990). As in our work, the differences are connected to the strength of the overturning, which differ between the two subsections by $0.7 \mathrm{~Sv}$ (they use a modified definition of the AMOC index). Also for the AMOC difference pattern in D'Orgeville and Peltier (2009) 
the similarities to the Type 3 transitions are remarkable. The maximum of the AMOC is displaced to the south in their simulation with a weaker overturning (control 1870). All these evidences suggest that the weak and strong AMOC phases, that are associated with the Type 3 transitions, represent the same two states which have been found in D'Orgeville and Peltier (2009). They however, focused on the two states rather than on the transitions and thus this study can contribute to a better understanding of the transition process itself.

For the Type 3 transitions, we find a new connection between the MLD in the DWF regions and the AMOC index. It has been already shown that in the low-resolution CCSM3 the AMOC strength is significantly coupled to the mean MLD South of Greenland and in the Irminger Sea with a lag of $\sim 10$ years, whereas no correlation with the MLD in the GIN Seas is found (D'Orgeville and Peltier, 2009). This result is confirmed here for all low-frequency AMOC variations excluding the Type 3 transitions, even though the lag is only 5 years. Also for the Type 3 transitions the AMOC lags the MIX $_{\text {west }}$ by 5-10 years, but additionally, the MLD in the GIN Seas and at the Iceland-Scotland ridge is changed. Based on the direction of the transition, MIX $_{\text {east }}$ begins its change prior to (transition from weak to strong), or after (transition from strong to weak) the AMOC change. Thus, we interpret the changes in the eastern DWF regions as the cause for the upward transitions, whereas the transitions from a strong to a weak AMOC are assumed to be initialized in the western DWF regions.

The atmospheric response (SAT, precipitation) to the Type 3 transitions is generally straightforward and driven by the SST. The regions with positive (negative) SST differences produce increased (decreased) SAT and precipitation. Consequently, the response over land is less pronounced and mostly restricted to coastal areas. One exception to this is Scandinavia where the SAT, and in parts also the precipitation, exhibit significant changes due to the transitions. This impact is of special interest, as proxies from northern Scandinavia - especially tree-rings - are used in most large-scale temperature reconstructions of the last millennium (IPCC, 2007). The general link between the SST in the Norwegian Sea and the Scandinavian SAT has also been found in proxy records for time-scales of decades to millennia (e.g., Moros et al., 2004; Büntgen et al., 2011).

Our results suggest that the temperature in this region is strongly influenced by circulation changes in the ocean that are not linearly linked to the external forcing. Thus, the Scandinavian SAT represents more a local response to internal climate variability of the atmosphere-ocean system than the external forcing signal. In comparison, proxy records for the last centuries do not exhibit a consistent picture. Using treering proxies of Northern Scandinavian summer temperature, Büntgen et al. (2011) emphasize the dominant impact of internal variability, while Helama et al. (2009) find a general agreement with the forcing-dependent large-scale tempera- ture variations. Nevertheless, both studies associate at least part of the regional temperature variations with ocean circulation changes. In contrast to the Type 3 transition response, others assume a broader impact of the AMOC on the temperature. Based on several terrestrial and marine proxy records Broecker (2000) and Denton and Broecker (2008) hypothesised that millennial oscillations of the AMOC strength may be responsible for the Medieval Warm Period-Little Ice Age variation, which is not supported by our results.

\section{Appendix A}

\section{Estimation methods for the atmospheric response}

For the first method, the linear regression coefficients between the RF and the investigated variable at each grid point are estimated. To exclude the effect of the Type 3 transitions, the TRal simulation is used for regression. The linear impact of the RF is then subtracted from the simulation. The volcanic forcing is handled differently, because its effect on the atmosphere is limited to 2-3 years following an eruption. Using the 21 strongest eruptions between 1500 to 2000 A.D., the mean response for the 4 years following an eruption is calculated at every grid point and, weighted by the strength of the individual eruption, the response is subtracted from the data. For the resulting time series, the strong and weak AMOC state are compared. As the external forcing level in the CTRL1000 simulation is constant, for this simulation the response according to the first method is calculated simply as the difference between the two periods.

The second method omits the uncertainties that are introduced due to the removal of the forcing effects. However, it can only be applied if two similar simulations are available that show different behavior. This is the case for the TRa ensemble simulations, as there is no Type 3 transition in TRa1. Thus, the TRa1 simulation is used as a reference case and for the other TRa simulations the anomalies are calculated with respect to TRa1.

Acknowledgements. This work has been supported by the National Centre of Competence in Research (NCCR) Climate funded by the Swiss National Science Foundation. CCR and TFS are funded by the European commission seventh framework programme, project Past4Future. DH also acknowledges the Swiss Federal Nuclear Safety Inspectorate (ENSI). The simulations were performed on an IBM Power 4, a CRAY XT3 and a CRAY XT5 at the Swiss National Supercomputing Centre (CSCS) in Manno. Constructive comments by two anonymous reviewers have improved the manuscript.

Edited by: U. Mikolajewicz 


\section{References}

Ammann, C. M., Meehl, G. A., Washington, W. M., and Zender, C. S.: A monthly and latitudinally varying volcanic forcing dataset in simulations of 20th century climate, Geophys. Res. Lett., 30, 1657, doi:10.1029/2003GL016875, 2003.

Blunier, T., Chappellaz, J., Schwander, J., Stauffer, B., and Raynaud, D.: Variations in atmospheric methane concentration during the Holocene epoch, Nature, 374, 46-49, doi:10.1038/374046a0, 1995.

Briegleb, B. P., Bitz, C. M., Hunke, E. C., Lipscomb, W. H., Holland, M. M., Schramm, J. L., and Moritz, R. E.: Scientific description of the sea ice component in the Community Climate System Model, version 3, NCAR Tech. Note, NCAR/TN463+STR, 70pp., 2004.

Briffa, K. R., Jones, P. D., Bartholin, T. S., Eckstein, D., Schweingruber, F. H., Karlen, W., Zetterberg, P., and Eronen, M.: Fennoscandian summers from AD-500 - temperature-changes on short and long timescales, Clim. Dynam., 7, 111-119, 1992.

Broecker, W. S.: Was a change in thermohaline circulation responsible for the Little Ice Age?, P. Natl. Acad. Sci. USA, 97, 13391342, 2000.

Brohan, P., Kennedy, J. J., Harris, I., Tett, S. F. B., and Jones, P. D.: Uncertainty estimates in regional and global observed temperature changes: A new data set from 1850, J. Geophys. Res.Atmos., 111, D12106, doi:10.1029/2005JD006548, 2006.

Bryan, F. O., Danabasoglu, G., Nakashiki, N., Yoshida, Y., Kim, D. H., Tsutsui, J., and Doney, S. C.: Response of the North Atlantic thermohaline circulation and ventilation to increasing carbon dioxide in CCSM3, J. Climate, 19, 2382-2397, 2006.

Büntgen, U., Raible, C. C., Frank, D., Helama, S., Cunningham, L., Hofer, D., Wilson, R., Nievergelt, D., Verstege, A., Timonen, M., Stenseth, N. C., and Esper, J.: Causes and consequences of Scandinavian summer temperatures, AD 500-2100, P. Natl. Acad. Sci. USA, in preparation, 2011.

Clark, P. U., Pisias, N. G., Stocker, T. F., and Weaver, A. J.: The role of the thermohaline circulation in abrupt climate change, Nature, 415, 863-869, 2002.

Collins, W. D., Bitz, C. M., Blackmon, M. L., Bonan, G. B., Bretherton, C. S., Carton, J. A., Chang, P., Doney, S. C., Hack, J. J., Henderson, T. B., Kiehl, J. T., Large, W. G., McKenna, D. S., Santer, B. D., and Smith, R. D.: The Community Climate System Model version 3 (CCSM3), J. Climate, 19, 2122-2143, 2006a.

Collins, W. D., Rasch, P. J., Boville, B. A., Hack, J. J., McCaa, J. R., Williamson, D. L., Briegleb, B. P., Bitz, C. M., Lin, S. J., and Zhang, M. H.: The formulation and atmospheric simulation of the Community Atmosphere Model version 3 (CAM3), J. Climate, 19, 2144-2161, 2006b.

Crowley, T. J.: Causes of climate change over the past 1000 years, Science, 289, 270-277, 2000.

Cubasch, U., Voss, R., Hegerl, G. C., Waszkewitz, J., and Crowley, T. J.: Simulation of the influence of solar radiation variations on the global climate with an ocean-atmosphere general circulation model, Clim. Dynam., 13, 757-767, 1997.

Cunningham, S. A., Kanzow, T., Rayner, D., Baringer, M. O., Johns, W. E., Marotzke, J., Longworth, H. R., Grant, E. M., Hirschi, J. J. M., Beal, L. M., Meinen, C. S., and Bryden, H. L.: Temporal variability of the Atlantic meridional overturning circulation at 26.5 degrees N, Science, 317, 935-938, doi:10.1126/science.1141304, 2007.

Dai, A., Hu, A., Meehl, G. A., Washington, W. M., and Strand, W. G.: Atlantic thermohaline circulation in a coupled general circulation model: Unforced variations versus forced changes, J. Climate, 18, 3270-3293, 2005.

Danabasoglu, G.: On multidecadal variability of the Atlantic meridional overturning circulation in the Community Climate System Model version 3, J. Climate, 21, 5524-5544, doi:10.1175/2008JCLI2019.1, 2008.

Delworth, T., Manabe, S., and Stouffer, R. J.: Interdecadal variations of the thermohaline circulation in a coupled oceanatmosphere model, J. Climate, 6, 1993-2011, 1993.

Denton, G. H. and Broecker, W. S.: Wobbly ocean conveyor circulation during the Holocene?, Quaternary Sci. Rev., 27, 1939-1950, doi:10.1016/j.quascirev.2008.08.008, 2008.

Dlugokencky, E. J., Houweling, S., Bruhwiler, L., Masarie, K. A., Lang, P. M., Miller, J. B., and Tans, P. P.: Atmospheric methane levels off: Temporary pause or a new steady-state?, Geophys. Res. Lett., 30, 1992, doi:10.1029/2003GL018126, 2003.

Dong, B. W. and Sutton, R. T.: Mechanism of interdecadal thermohaline circulation variability in a coupled ocean-atmosphere GCM, J. Climate, 18, 1117-1135, 2005.

D'Orgeville, M. and Peltier, W. R.: Implications of both statistical equilibrium and global warming simulations with CCSM3. Part II: On the multidecadal variability in the North Atlantic basin, J. Climate, 22, 5298-5318, 2009.

Enfield, D. B., Mestas-Nuñez, A. M., and Trimble, P. J.: The Atlantic multidecadal oscillation and its relation to rainfall and river flows in the continental US, Geophys. Res. Lett., 28, 2077-2080, 2001.

Etheridge, D. M., Steele, L. P., Langenfelds, R. L., Francey, R. J., Barnola, J. M., and Morgan, V. I.: Natural and anthropogenic changes in atmospheric $\mathrm{CO}_{2}$ over the last 1000 years from air in Antarctic ice and firn, J. Geophys. Res.-Atmos., 101, 4115-4128, 1996.

Flückiger, J., Dallenbach, A., Blunier, T., Stauffer, B., Stocker, T. F., Raynaud, D., and Barnola, J. M.: Variations in atmospheric $\mathrm{N}_{2} \mathrm{O}$ concentration during abrupt climatic changes, Science, 285, 227-230, 1999.

Flückiger, J., Monnin, E., Stauffer, B., Schwander, J., Stocker, T. F., Chappellaz, J., Raynaud, D., and Barnola, J. M.: Highresolution Holocene $\mathrm{N}_{2} \mathrm{O}$ ice core record and its relationship with $\mathrm{CH}_{4}$ and $\mathrm{CO}_{2}$, Global Biogeochem. Cy., 16, 1010, doi:10.1029/2001GB001417, 2002.

Frank, D. C., Esper, J., Raible, C. C., Büntgen, U., Trouet, V., Stocker, B., and Joos, F.: Ensemble reconstruction constraints on the global carbon cycle sensitivity to climate, Nature, 463, 527-U143, doi:10.1038/nature08769, 2010.

Frankcombe, L. M., von der Heydt, A., and Dijkstra, H. A.: North Atlantic Multidecadal Climate Variability: An Investigation of Dominant Time Scales and Processes, J. Climate, 23, 36263638, doi:10.1175/2010JCLI3471.1, 2010.

Fröhlich, C. and Lean, J.: Solar radiative output and its variability: Evidence and mechanisms, Astron. Astrophys. Rev., 12, 273320, 2004.

Goosse, H. and Renssen, H.: Regional response of the climate system to solar forcing: The role of the ocean, Space Sci. Rev., 125, 227-235, doi:10.1007/s11214-006-9059-0, 2006.

Gregory, J. M., Dixon, K. W., Stouffer, R. J., Weaver, A. J., Driess- 
chaert, E., Eby, M., Fichefet, T., Hasumi, H., Hu, A., Jungclaus, J. H., Kamenkovich, I. V., Levermann, A., Montoya, M., Murakami, S., Nawrath, S., Oka, A., Sokolov, A. P., and Thorpe, R. B.: A model intercomparison of changes in the Atlantic thermohaline circulation in response to increasing atmospheric $\mathrm{CO}_{2}$ concentration, Geophys. Res. Lett., 32, L12703, doi:10.1029/2005GL023209, 2005.

Helama, S., Timonen, M., Holopainen, J., Ogurtsov, M. G., Mielikäinen, K., Eronen, M., Lindholm, M., and Merilainen, J.: Summer temperature variations in Lapland during the Medieval Warm Period and the Little Ice Age relative to natural instability of thermohaline circulation on multi-decadal and multi-centennial scales, J. Quaternary Sci., 24, 450-456, doi:10.1002/jqs.1291, 2009.

Hurrell, J. W., Visbeck, M., Busalacchi, A., Clarke, R. A., Delworth, T. L., Dickson, R. R., Johns, W. E., Koltermann, K. P., Kushnir, Y., Marshall, D., Mauritzen, C., McCartney, M. S., Piola, A., Reason, C., Reverdin, G., Schott, F., Sutton, R., Wainer, I., and Wright, D.: Atlantic climate variability and predictability: A CLIVAR perspective, J. Climate, 19, 5100-5121, 2006.

IPCC: Climate Change 2001: The Scientific Basis. Contribution of Working Group I to the Third Assessment Report of the Intergovernmental Panel on Climate Change, Cambridge University Press, Cambridge, United Kingdom and New York, NY, USA, 2001.

IPCC: Climate Change 2007: The Physical Science Basis. Contribution of Working Group I to the Forth Assessment Report of the Intergovernmental Panel on Climate Change, Cambridge University Press, Cambridge, United Kingdom and New York, NY, USA, 2007.

Jungclaus, J. H., Haak, H., Latif, M., and Mikolajewicz, U.: ArcticNorth Atlantic interactions and multidecadal variability of the meridional overturning circulation, J. Climate, 18, 4013-4031, 2005.

Keeling, C. D. and Whorf, T. P.: Atmospheric $\mathrm{CO}_{2}$ records from sites in the SIO air sampling network, in: Trends: A Compendium of Data on Global Change, Carbon Dioxide Information Analysis Center, Oak Ridge National Laboratory, U.S. Department of Energy, Oak Ridge, TN, 2005.

Kiehl, J. T., Shields, C. A., Hack, J. J., and Collins, W. D.: The climate sensitivity of the Community Climate System Model version 3 (CCSM3), J. Climate, 19, 2584-2596, 2006.

Kristensen, D. K., Sejrup, H. P., Haflidason, H., Berstad, I. M., and Mikalsen, G.: Eight-hundred-year temperature variability from the Norwegian continental margin and the North Atlantic thermohaline circulation, Paleoceanography, 19, PA2007, doi:10.1029/2003PA000960, 2004.

Lean, J., Beer, J., and Bradley, R.: Reconstruction of solar irradiance since 1610 - implications for climate-change, Geophys. Res. Lett., 22, 3195-3198, 1995.

Meehl, G. A., Washington, W. M., Santer, B. D., Collins, W. D., Arblaster, J. M., Hu, A. X., Lawrence, D. M., Teng, H. Y., Buja, L. E., and Strand, W. G.: Climate change projections for the twenty-first century and climate change commitment in the CCSM3, J. Climate, 19, 2597-2616, 2006.

Moros, M., Emeis, K., Risebrobakken, B., Snowball, I., Kuijpers, A., McManus, J., and Jansen, E.: Sea surface temperatures and ice rafting in the Holocene North Atlantic: Climate influences on Northern Europe and Greenland, Quaternary Sci. Rev., 23,
2113-2126, doi:10.1016/j.quascirev.2004.08.003, 2004.

Mudelsee, M.: Ramp function regression: A tool for quantifying climate transitions, Comput. Geosci., 26, 293-307, 2000.

Oleson, K. W., Dai, Y., Bonan, G., Rosilovich, M., Dickinson, R., Dirmeyer, P., Hoffman, F., Houser, P., Levis, S., Niu, G.-Y., Thornton, P., Vertenstein, M., Yang, Z.-L., and Zeng, X.: Technical description of the Community Land Model (CLM), NCAR Tech. Note, NCAR/TN-461+STR, 173pp., 2004.

Ottera, O. H., Bentsen, M., Drange, H., and Suo, L. L.: External forcing as a metronome for Atlantic multidecadal variability, Nat. Geosci., 3, 688-694, doi:10.1038/NGEO955, 2010.

Renold, M., Raible, C. C., Yoshimori, M., and Stocker, T. F.: Simulated resumption of the North Atlantic meridional overturning circulation - Slow basin-wide advection and abrupt local convection, Quaternary Sci. Rev., 29, 101-112, doi:10.1016/j.quascirev.2009.11.005, 2010.

Schmittner, A., Saenko, O. A., and Weaver, A. J.: Coupling of the hemispheres in observations and simulations of glacial climate change, Quaternary Sci. Rev., 22, 659-671, 2003.

Servonnat, J., Yiou, P., Khodri, M., Swingedouw, D., and Denvil, S.: Influence of solar variability, $\mathrm{CO}_{2}$ and orbital forcing between 1000 and 1850 AD in the IPSLCM4 model, Clim. Past, 6, 445-460, doi:10.5194/cp-6-445-2010, 2010.

Sicre, M. A., Jacob, J., Ezat, U., Rousse, S., Kissel, C., Yiou, P., Eiriksson, J., Knudsen, K. L., Jansen, E., and Turon, J. L.: Decadal variability of sea surface temperatures off North Iceland over the last 2000 years, Earth Planet. Sc. Lett., 268, 137-142, doi:10.1016/j.eps1.2008.01.011, 2008.

Smith, R. S. and Gent, P. R.: Reference manual for the Parallel Ocean Program (POP), ocean component of the Community Climate System Model (CCSM2.0 and 3.0), Los Alamos National Laboratory Tech. Rep. LA-UR-02-2484, 75pp., 2004.

Steinhilber, F., Beer, J., and Fröhlich, C.: Total solar irradiance during the Holocene, Geophys. Res. Lett., 36, L19704, doi:10.1029/2009GL040142, 2009.

Stenchikov, G., Hamilton, K., Stouffer, R. J., Robock, A., Ramaswamy, V., Santer, B., and Graf, H. F.: Arctic Oscillation response to volcanic eruptions in the IPCC AR4 climate models, J. Geophys. Res.-Atmos., 111, D07107, doi:10.1029/2005JD006286, 2006.

Stenchikov, G., Delworth, T. L., Ramaswamy, V., Stouffer, R. J., Wittenberg, A., and Zeng, F. R.: Volcanic signals in oceans, J. Geophys. Res.-Atmos., 114, D16104, doi:10.1029/2008JD011673, 2009.

Stocker, T. F.: Past and future reorganizations in the climate system, Quaternary Sci. Rev., 19, 301-319, 2000.

Sutton, R. T. and Hodson, D. L. R.: Atlantic ocean forcing of North American and European summer climate, Science, 309, 115118, doi:10.1126/science.1109496, 2005.

Thompson, A. M., Butler, J. H., Daube, B. C., Dutton, G. S., Elkins, J. W., Hall, B. D., Hurst, D. F., King, D. B., Kline, E. S., Lafleur, B. G., Lind, J., Lovitz, S., Mondeel, D. J., Montzka, S. A., Moore, F. L., Nance, J. D., Neu, J. L., Romanshkin, P. A., Scheffer, A., and Snible, W. J.: Halocarbons and other atmospheric trace species, in: Climate Monitoring and Diagnostics Laboratory, Summary Report No. 27, 115-135, NOAA CMDL, Boulder, CO, 2004.

Timmermann, A., Latif, M., Voss, R., and Grotzner, A.: Northern Hemispheric interdecadal variability: A coupled air-sea mode, J. 
Climate, 11, 1906-1931, 1998.

van der Schrier, G., Weber, S. L., and Drijfhout, S. S.: Sea level changes in the North Atlantic by solar forcing and internal variability, Clim. Dynam., 19, 435-447, doi:10.1007/s00382-0020235-y, 2002.

Yeager, S. G., Shields, C. A., Large, W. G., and Hack, J. J.: The low-resolution CCSM3, J. Climate, 19, 2545-2566, 2006.

Yoshimori, M., Raible, C. C., Stocker, T. F., and Renold, M.: Simulated decadal oscillations of the Atlantic meridional overturning circulation in a cold climate state, Clim. Dynam., 34, 101-121, doi:10.1007/s00382-009-0540-9, 2010.
Zorita, E., von Storch, H., Gonzalez-Rouco, F. J., Cubasch, U., Luterbacher, J., Legutke, S., Fischer-Bruns, I., and Schlese, U.: Climate evolution in the last five centuries simulated by an atmosphere-ocean model: global temperatures, the North Atlantic Oscillation and the Late Maunder Minimum, Meteorol. Z., 13, 271-289, doi:10.1127/0941-2948/2004/0013-0271, 2004. 